\title{
Tuberculose resistente nos indivíduos HIV positivos em cinco municípios da Baixada Santista- SP
}

\section{Luciana Martins Rozman}

Dissertação de Mestrado apresentada ao Programa de Pós-Graduação em Saúde Pública da Faculdade de Saúde Pública da Universidade de São Paulo para obtenção do título de Mestre em Saúde Pública

Área de Concentração: Epidemiologia Orientador: Prof. Dr.Augusto Hasiak Santo

São Paulo 2004

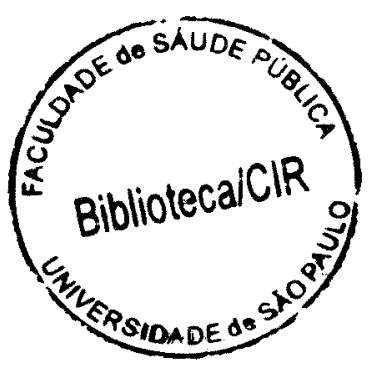


Autorizo exclusivamente para fins acadêmicos e científicos, a reprodução total ou parcial desta dissertação, por processos fotocopiadores. Ao usá-lo, cite a fonte.

Data: novembro/2004

Assinatura: Pagmon

$$
45504 / 2005 \text { doe }
$$


Aos meus pais pelos ensinamentos de vida 


\section{AGRADECIMENTOS}

Ao meu orientador, Prof. Dr. Augusto Hasiak Santo, os meus sinceros agradecimentos pelo constante incentivo na concretização deste trabalho.

A Marcia da Silva Martins, pela amizade e fundamental participação na aplicação dos questionários para coleta das informações.

Ao Dr. José Eluf Neto pelo companheirismo e pela inestimável colaboração prestada.

Ao Ivaldo Olímpio da Silva do Departamento de Medicina Preventiva da USP pela orientação da análise estatística de parte dos dados.

A Dra Liliana Aparecida Zamarioli Youssef, Diretora técnica pelo Instituto Adolfo Lutz de Santos, pela constante colaboração colocando à disposição os dados laboratoriais. Meus agradecimentos também as funcionárias Andréia Gobetti e Clemira Martins.

A Margarete Silva Jordani, Antônio Benedito Marangone Camargo e Luiz Patricio Ortiz Flores da Fundação Sistema Estadual de Análise de Dados (SEADE) do Estado de São Paulo pelas informações sobre causa de óbito.

Aos Responsáveis Técnicos das unidades de saúde pela colaboração e apoio.

Aos funcionários das unidades de saúde pela atenção e colaboração.

Ao meu marido Dr. Mauro Abrahão Rozman por me abrir as portas da epidemiologia com competência e paixão. Pela paciência, dedicação, 
desprendimento e sugestões em todas as fases deste estudo. A ele dedico este trabalho. 


\section{RESUMO}

Rozman LM. Tuberculose resistente em indivíduos HIV positivos em cinco municípios da Baixada Santista - SP. São Paulo, 2004. [Dissertação de Mestrado - Faculdade de Saúde Pública da USP].

Desde o início dos anos 90 vários estudos relatam aumento do número de casos de Mycobacterium tuberculosis resistentes às drogas tuberculostáticas, inclusive nos países desenvolvidos, com alta prevalência entre os pacientes HIV+. Objetivos: avaliar a frequência de resistência, o perfil de sensibilidade do Mycobacterium tuberculosis às drogas e os fatores predisponentes à resistência entre os indivíduos HIV positivos nos municípios de Santos, São Vicente, Cubatão, Praia Grande e Guarujá. Métodos: Levantamento dos prontuários de 301 pacientes que apresentaram resultado de cultura positivo e teste de sensibilidade às drogas tuberculostáticas entre 1993 e 2003. Resultados: A resistência às drogas foi diagnosticada em 57 pacientes $(18,9 \%)$ com a seguinte distribuição: $32(10,6 \%)$ apresentaram TB multirresistente (resistência a pelo menos rifampicina e isoniazida); $4(1,3 \%)$ casos apresentaram resistência a duas ou mais drogas e 21 (7\%) monorresistência. A resistência adquirida foi observada em $70,1 \%$ dos casos. Não houve associação entre tuberculose resistente e as variáveis: alcoolismo, uso de drogas injetáveis, contagem de $\mathrm{CD} 4+$, falta de domicílio e uso de antiretrovirais. As variáveis estatisticamente associadas a TB resistente foram: tratamento anterior com tuberculostáticos, tempo de diagnóstico de HIV e hospitalização prévia. Em análise multivariada apenas tratamento anterior, ajustado por faixa etária, mostrou-se estatisticamente associado $(\mathrm{OR}=5,49$ : IC95\% 2,60-11,60). Conclusões: A ocorrência de resistência em $18,9 \%$ dos casos e multirresistência em aproxidamamente $10 \%$ confirmam a 
relevância deste problema entre pacientes HIV+ na Baixada Santista. Entre os fatores de risco analisados apenas tratamento anterior com tuberculostáticos esteve estatisticamente associado.

Descritores: Tuberculose, HIV, resistência às drogas 


\section{SUMMARY}

\section{Rozman LM. Drug resistance tuberculosis in HIV patients in Baixada}

Santista - São Paulo - Brazil. São Paulo, 2004. [Master's Dissertation Faculdade de Saúde Pública da USP].

Since the early 90's, several studies have reported an increase in the number of drug resistance Mycobacterium tuberculosis cases, even in developed countries, with high prevalence between HIV positive patients. Objective: to evaluate the sensitivity patterns of $M$. tuberculosis, the rate of resistance and its predisposing factors among HIV positive patients in Santos, São Vicente, Cubatão, Praia Grande e Guarujá. Methods: Review of the medical charts of 301 patients who had positive cultures for M. tuberculosis and sensitivity tests from 1993 to 2003. Results: resistance occurred in 57 patients $(18,9 \%)$, with the following pattern: $32(10,6 \%)$ exhibited multidrug-resistant tuberculosis (resistance to at least rifampicin and isoniazid); 4 (1,3\%) cases exhibited resistance to two or more drugs and 21 (7\%) exhibited resistant strains to a single drug. Acquired resistance was observed in $70,1 \%$ cases. Drug resistance tuberculosis wasn't associated with: alcohol abuse, injecting drug use, CD4+ lymphocytes count, homelessness and antiretroviral use. The variables statistically significantly associated with drug resistance were: previous tuberculosis treatment, duration of HIV diagnoses and previous hospitalization. In logistic regression analysis only previous tuberculosis treatment, adjusted by age, remained as independent risk factor ( $\mathrm{OR}=5,49$ : IC95\% 2,60-11,60). Conclusion: drug resistance to at least one drug in $18,9 \%$ and multidrug resistance in $10,6 \%$ of the cases point out the importance of this problem in HIV patients at Baixada 
Santista. Of the analyzed risk factors only previous tuberculosis treatment was statistically significantly associated.

Descriptors: Tuberculosis , HIV, drug resistance 


\section{LISTA DE ABREVIATURAS}

ARV - Antiretroviral

CDC - Centres for Disease Control and Prevention (Centro de Controle e Prevenção de doenças)

CID 10 - Classificação Internacional de Doenças - Décima edição

CRAIDS- Centro de Referência em AIDS de Santos

DOT- Directly observed treatment (Tratamento diretamente observado)

DOTS- Directly observed treatment, short-course (Tratamento diretamente observado de curta duração)

E - Etambutol

HAART - Highly active antiretroviral therapy (Terapia antiretroviral combinada potente)

HDWR - Hospital Dia William da Rocha

I - Isoniazida

IAL- Instituto Adolfo Lutz

IUATLD- International Union against Tuberculosis and Lung Disease

OMS - Organização Mundial de Saúde

P - Pirazinamida

PAS - Ácido para-amino salicílico

PPD- Prova Tuberculínica cutânea

R - Rifampicina 
RFLP- Restriction fragment length polymorfism

S - Estreptomicina

SAE- PG- Serviço de Especialidades de Praia Grande

SAE-SV- Serviço de Especialidades de São Vicente

SEADE - Fundação Sistema Estadual de Análise de Dados do Estado de São Paulo

TB - Tuberculose

TBMR - Tuberculose multirresistente

TBS - Tuberculose sensível 


\section{LISTA DE TABELAS}

Tabela 1 - Distribuição dos casos de TB/HIV segundo contagem de linfócitos CD4+ no sangue periférico, Baixada Santista -1993-2003 pág. 42

Tabela 2 - Distribuição dos casos de TB/HIV segundo tempo (em anos) de evolução do HIV na data do diagnóstico de TB, Baixada Santista -1993-2003. .pág. 43

Tabela 3 - Distribuição dos casos de TB/HI segundo uso de ARV* ou HAART** antes do diagnóstico de TB, Baixada Santista -1993-2003. pág. 43

Tabela 4 - Distribuição dos casos de TB/HIV segundo condição de moradia, consumo de bebidas alcoólicas e uso de drogas injetáveis, Baixada Santista 19932003. pág. 44

Tabela 5 - Distribuição do número de internações prévias ao início de tratamento de tuberculose dos casos de TB/HIV segundo hospital, Baixada Santista- 19932003. pág. 45

Tabela 6 - Distribuição dos casos de TB/HIV segundo perfil de sensibilidade do M. tuberculosis às drogas, Baixada Santista 1993-2003. pág.48

Tabela 7 - Distribuição dos casos de TB resistentes e sensíveis em indivíduos HIV positivos segundo tratamento prévio com drogas antituberculose, Baixada Santista- 1993-2003. ..pág.50

Tabela 8 - Distribuição dos casos de tuberculose resistente em indivíduos HIV positivos segundo padrão de resistência às drogas anti-tuberculose, Baixada Santista - 1993-2003 pág. 51

Tabela 9 - Distribuição dos casos de TB sensíveis e casos de TB resistentes em indivíduos HIV positivos segundo município de atendimento, Baixada Santista1993-2003 .pág. 52

Tabela 10 - Distribuição dos casos de TB sensíveis e resistentes em indivíduos HIV positivos segundo ano de diagnóstico de tuberculose, Baixada Santista 1993-2003. pág. 53 
Tabela 11. Análise univariada para avaliação da associação entre TB resistente e as variáveis de estudo .pág.55

Tabela 12 - Análise multivariada segundo variáveis explicativas da resistência às drogas anti-tuberculose, ajustada por faixa etária........................................pág. 56

Tabela 13 - Distribuição dos 111 óbitos de 301 pacientes TB/HIV segundo causa associada de morte, Baixada Santista 1993-2003...........................................pág.57 


\section{ÍNDICE}

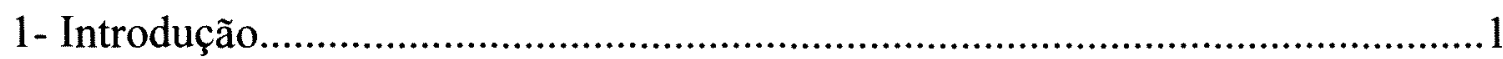

1.1 Tuberculose

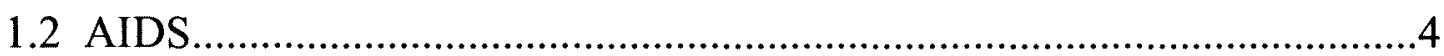

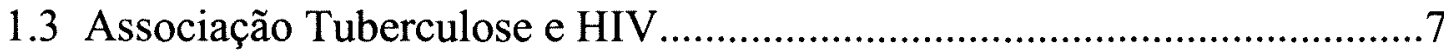

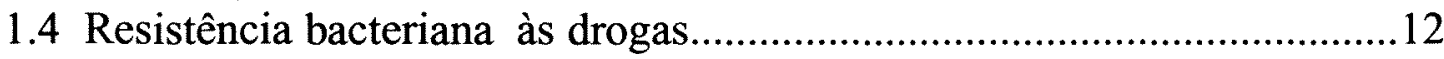

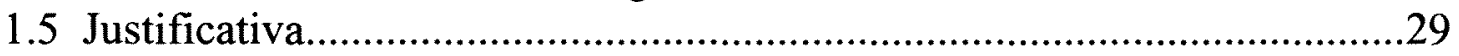

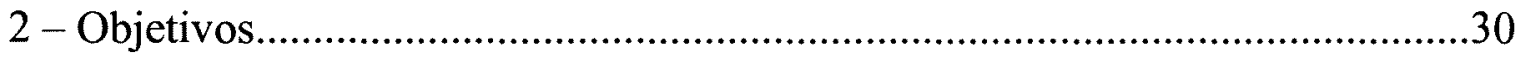

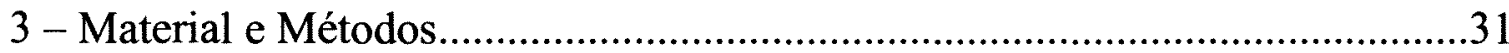

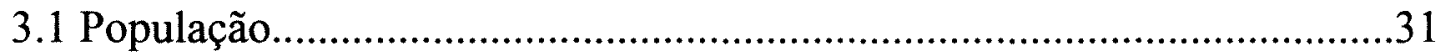

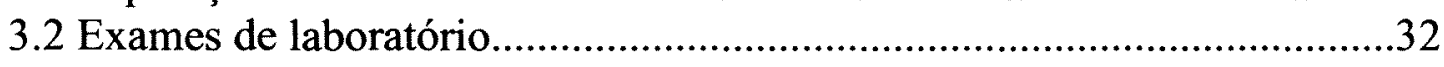

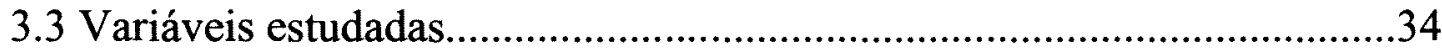

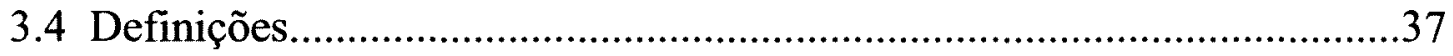

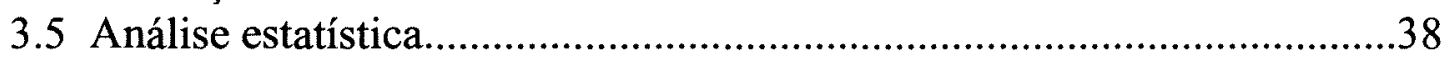

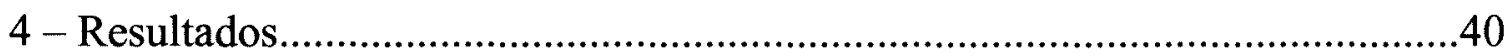

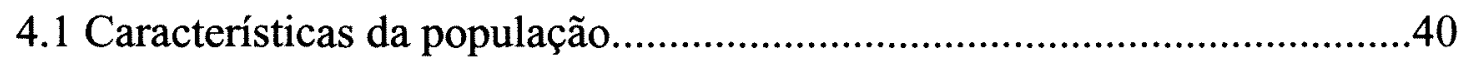

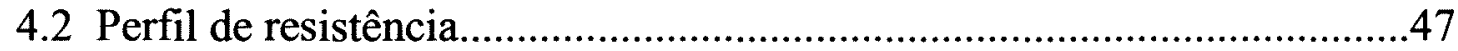

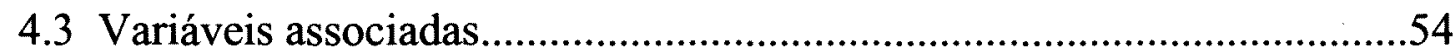

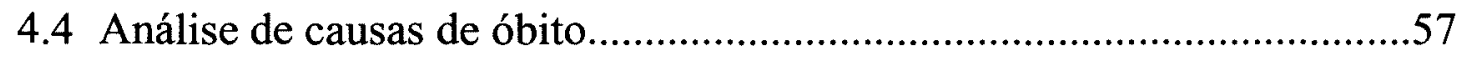

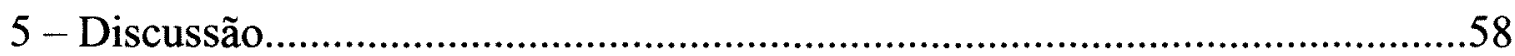

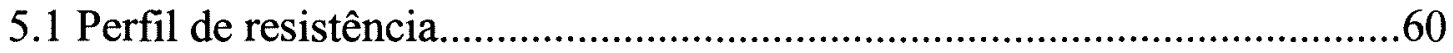

5.2 Associação entre variáveis estudadas e resistência às drogas...................65

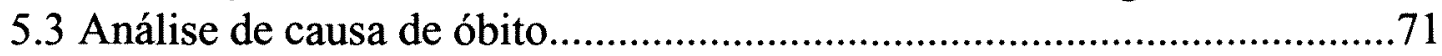

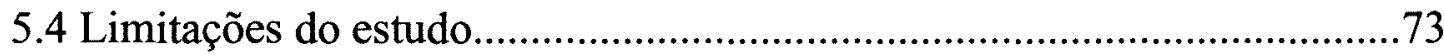

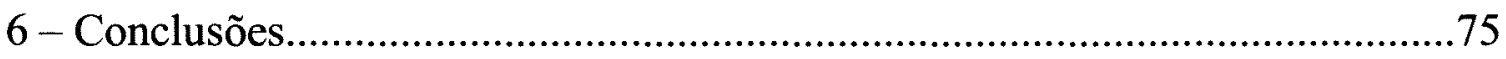

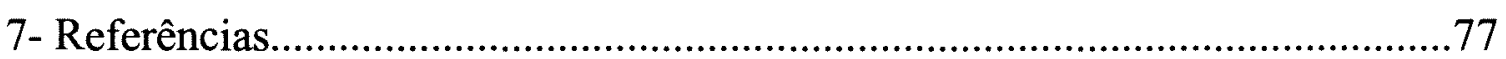

Anexo

Anexo 1- Formulário para pesquisa de prontuário 


\section{1-Introdução}

\section{1- Tuberculose}

A Tuberculose (TB) continua sendo um importante problema de saúde pública, especialmente em países em desenvolvimento (MINISTÉRIO DA SAÚDE 2000). No ano de 2001 foram notificados 3,8 milhões de casos de TB mundialmente. Segundo a Organização Mundial de Saúde (OMS) este número representa apenas $45 \%$ dos 8,5 milhões de casos estimados para esse ano (WHO, 2003).

A OMS estima que entre 2002 e 2020 aproximadamente 1 bilhão de pessoas serão infectadas com o Mycobacterium tuberculosis, com mais de 150 milhões de doentes e 36 milhões de óbitos por TB.(WHO, 2002).

A incidência da doença está aumentando em várias regiões do mundo desde a década de 80 (NARAIN et al. 1992). Nos anos 60 e 70, por exemplo, entre 1 e 1,8 milhões de novos casos eram notificados anualmente à OMS, enquanto que nos anos 80 o número de casos notificados aumentou para 2,5 milhões (LEOWSKI e MILLER 1992).

Nos Estados Unidos a incidência da TB alcançou sua estabilização até 1985. Entre 1985 e 1992, o número de casos aumentou aproximadamente 3\% ao ano até alcançar em 1992 a incidência de 10,5 casos por 100 mil habitantes 
(26.673 casos). A partir de 1993, o número de casos diminuiu anualmente até alcançar 22.813 casos em 1995.(GARCIA et al. 1995)

Em 1991 foram notificados 231.608 casos no continente Europeu (região Europa da OMS). No ano de 1996, 315.892 casos foram notificados a OMS sendo que o coeficiente de incidência foi menor que 20 por 100.000 habitantes em 21 países, todos situados na parte oeste da Europa . Coeficientes acima de 20 casos por 100.000 habitantes foram registrados em 29 países, todos localizados no leste Europeu, com exceção de Portugal e Espanha. (RÜSCH-GERDES 1999).

Durante os anos oitenta, o número de casos também aumentou nos países em desenvolvimento. A Tanzânia notificou 22.544 casos em 1990, um aumento de $86 \%$ em relação aos 12.089 casos notificados em 1984. Outros países da África como Burundi, Malawi e Zambia apresentaram aumento no número de casos de $140 \%, 180 \%$ e $154 \%$ respectivamente no mesmo período. (NARAIN et al. 1992)

Este aumento no número de casos tem sido atribuído principalmente à deterioração das medidas de controle, precárias condições econômicas e à epidemia HIV/AIDS (RIEDER et al. 1989, BRUDNEY et al. 1991, BARNES et al. 1991, HIJJAR 1992, CATWELL et al.1994, GARCIA et al. 1995, WHO 2002).

Em 1993 a OMS declarou a TB uma emergência global e após avaliar os fatores e dimensão do problema, desenvolveu a estratégia de controle 
chamada DOTS (directly observed treatment, short-course). Esta estratégia é baseada em cinco princípios:

- Compromisso dos governos em apoiar as atividades de controle da TB;

- Deteç̧ão de casos por meio de baciloscopia entre pacientes sintomáticos que se apresentem aos serviços de saúde;

- Esquema de tratamento padronizado de seis meses para todos os casos confirmados com baciloscopia positiva. Estes casos devem receber tratamento supervisionado (DOT) pelo menos nos 2 primeiros meses;

- Garantia de abastecimento ininterrupto das drogas para o tratamento;

- Sistema de registro de dados que permita acesso aos resultados de tratamento de cada paciente e do programa de controle de TB (MAHER 1999)

Em 1997, 102 países adotavam a estratégia DOTS (MAHER et al. 1999). No final de 2001, este número aumentou para 155 países (WHO 2003). No entanto, segundo avaliação da OMS, no ano 2000 , apenas um quarto dos casos eram tratados com base na estratégia DOTS (DYE et al. 2002).

Nos últimos anos a incidência de TB apresenta tendência à estabilidade com exceção de países do leste europeu e países africanos com alta prevalência de HIV. A OMS estima que entre os anos de 1997 e 2000 a incidência de TB tenha aumentado $6 \%$ ao ano nos países do leste europeu e 5\% nos países africanos com alta prevalência de HIV (WHO 2003). 
O Brasil é o $15^{\circ}$ colocado em numero de casos estimados (WHO 2003), apresenta o maior número de casos da América Latina (ROSSETTI et al. 2002) e está entre os 22 países considerados prioritários pela OMS (NATAL et al. 2003).

O Estado de São Paulo apresenta o maior número absoluto de casos de TB, com 20.501 notificações em 2003 (CENTRO DE VIGILÂNCIA EPIDEMIOLÓGICA 2003). No Estado, a região da Baixada Santista apresenta os maiores coeficientes de incidência (SECRETARIA DE ESTADO DA SAÚDE 2000).

\section{2 - AIDS}

A síndrome da imunodeficiência adquirida (AIDS) foi descrita pela primeira vez em 1981 nos Estados Unidos (CHIN e MANN 1989).A epidemia da infecção pelo vírus da imunodeficiência humana (HIV) e da AIDS representa fenômeno global, dinâmico e instável, cuja forma de ocorrência nas diferentes regiões do mundo depende, entre outros determinantes, do comportamento humano individual e coletivo. A AIDS destaca-se entre as enfermidades infecciosas emergentes pela grande magnitude e extensão dos danos causados às populações e, desde a sua origem, cada uma de suas 
características e repercussões tem sido exaustivamente discutida pela comunidade científica e pela sociedade em geral (BRITO et al. 2001).

Até meados de 1996 estimava-se que haveria cerca de 22 milhões de pessoas com a infecção pelo HIV ou com AIDS em todo mundo (AIDSCAP 1996).

De acordo com estimativas da UNAIDS/OMS, ao final do ano de 2003, 40 milhões de pessoas estavam infectadas pelo HIV, sendo que 5 milhões foram infectados naquele ano. Estima-se também que 3 milhões de pessoas tenham morrido de doenças relacionadas à AIDS (UNAIDS 2003).

O número de pessoas vivendo com HIV/AIDS continua crescendo em muitas regiões do mundo principalmente na África sub-Sahariana, no Leste Europeu e Ásia (UNAIDS 2003).

A África sub-Sahariana é a região com maior número de casos. A OMS estima que mais da metade dos indivíduos infectados com HIV em todo o mundo (26,6 milhões de pessoas) viva nesta região (UNAIDS 2003)

Os países mais atingidos do Leste Europeu são Rússia, Ucrânia, Estônia, Latvia e Lituania. Estima-se que 1,5 milhões de pessoas estejam infectadas e que 30 mil tenham morrido em 2003 (UNAIDS 2003).

Nos países industrializados, nota-se uma diminuição no número de casos de Aids decorrente da terapêutica anti-retroviral combinada, que retarda o desenvolvimento da doença (UNAIDS 2003; HALL et al. 2003), e de medidas de prevenção iniciadas na década de 80 , cujos efeitos estariam se 
tornando aparentes (WHO 1998). A estimativa é de 1,6 milhões de pessoas vivendo com HIV até 2003, a maioria de seguimentos marginalizados da sociedade incluindo negros e imigrantes (UNAIDS 2003).

Nos países da América Latina e Caribe estima-se que neste mesmo ano tenham ocorrido 100 mil óbitos por doenças relacionadas à AIDS sendo depois da África sub-Sahariana a região do mundo com maior número de óbitos pela doença. Estima-se que até o ano de 2003, 2 milhões de pessoas foram infectadas com HIV (UNAIDS 2003).

No Brasil até 31/12/2003 foram notificados 310.310 casos da doença. (MINISTÉRIO DA SAÚDE 2003).

Segundo análise do Ministério da Saúde tem ocorrido desaceleração da incidência da AIDS devido a medidas preventivas, saturação dos segmentos da população sob risco, mudança comportamental e à terapia anti-retroviral. (MINISTÉRIO DA SAÚDE 2001)

Epidemia restrita a alguns círculos cosmopolitas das denominadas metrópoles nacionais - São Paulo e Rio de Janeiro - e marcadamente masculina, que atingia prioritariamente homens com prática sexual homossexual e hemofilicos no início dos anos 80 , depara-se hoje, com quadro marcado pelos processos da heterossexualização, da feminização, da interiorização e da pauperização. $\mathrm{O}$ aumento da transmissão pelo contato heterossexual resulta em crescimento substancial de casos em mulheres, o que 
vem sendo apontado como o mais importante fenômeno para o atual momento da epidemia (BRITO et al. 2000).

No Estado de São Paulo foram notificados, até 2003, 140.728 casos de AIDS, sendo a unidade federativa que apresenta o maior número de notificações. A. cidade de Santos é a décima segunda em coeficiente de incidência acumulada de AIDS do país. Outras cidades da Baixada Santista como Cubatão, São Vicente e Guarujá ocupam o $15^{\circ}, 19^{\circ}$ e $21^{\circ}$ lugares, respectivamente, em incidência no Brasil (MINISTÉRIO DA SAUUDE 2003).

\section{3 - Associação Tuberculose e HIV}

A infecção pelo HIV tem exercido um substancial impacto na epidemia global da tuberculose (DALEY et al. 1992; GARCÍA et al. 1995). Tuberculose é uma das mais comuns causas de morbidade e a mais comum causa de mortalidade entre pacientes HIV positivos em países em desenvolvimento (MC DONALD et al. 1999; CORBETT et al. 2002)

Diversos estudos têm demonstrado que pessoas co-infectadas com o Mycobacterium tuberculosis e com o vírus HIV têm maior risco de adquirir a doença tuberculosa (NARAIN et al. 1992; DALEY et al. 1992; BRAUN et al. 1992). Este fato se deve a fisiopatologia da TB. Após a implantação do $M$. tuberculosis no alvéolo pulmonar, inicia-se um processo imunológico 
complexo, que visa a destruição da bactéria e a contenção da infecção. Neste processo imunológico é de fundamental importância um dos subtipos de linfócitos $\mathrm{T}$, conhecido como $\mathrm{CD} 4$, sem os quais o organismo não consegue desenvolver uma imunidade protetora (WEISSLER 1993).

Na AIDS, as infecções oportunistas devem-se a deficiências do sistema imunológico, sendo a perda de linfócitos $\mathrm{T}$ tipo $\mathrm{CD} 4$ uma das primeiras anormalidades observadas, seguida pela deficiência de funcionamento dos macrófagos e monócitos. Acredita-se que estas disfunções, encontradas nos indivíduos infectados pelo HIV, sejam responsáveis pelo maior risco de reativação da infecção tuberculosa e pelo maior risco de progressão para doença a partir da infecção inicial. Além disso, o desenvolvimento de tuberculose primária ocorre com maior frequência e mais rapidamente em indivíduos HIV positivos (FISCHE et al. 1992, LEE et al. 1995 GORDIN et al. 1996).

Enquanto o indivíduo HIV negativo tem $10 \%$ de risco de adoecimento por tuberculose por toda a sua vida (GARCÍA et al. 1995; KAYE e FRIEDEN 1996), estima-se que o risco anual entre os indivíduos HIV positivos coinfectados com o bacilo da TB seja muito alto, entre 8 a 10\% (MURRAY et al. 1990).

O impacto da epidemia pelo HIV na situação epidemiológica da tuberculose depende de diversos fatores, entre eles:

- Prevalência do HIV numa comunidade e sua tendência; 
- Prevalência da infecção tuberculosa na população geral na faixa etária de 1549 anos;

- Taxa de conversão da tuberculose infecção para tuberculose doença ;

- Nível e tendência do risco médio de infecção tuberculosa ;

- Taxa de detecção de novos casos de TB, recidiva e abandono e taxa de cura de pacientes bacilíferos (STYLBO 1991).

Nos Estados Unidos, no período de 1985 a 1992, ocorreram 52.100 casos de TB acima dos esperados e destes estima-se que $50 \%$ poderiam ser atribuídos à infecção pelo HIV (CATWELL et al. 1994).

Na Europa a infecção por HIV não agravou a situação epidemiológica da tuberculose, principalmente devido a baixa prevalência da infecção tuberculosa nos países da Europa Ocidental, mas um impacto um pouco maior ocorreu em algumas cidades da Espanha e Itália, países em que há maior proporção de dependentes de drogas entre os casos de AIDS (RIEDER 1995). A taxa de incidência da tuberculose na Catalúnia (nordeste da Espanha) aumentou $50 \%$ entre 1987 e 1993 e $60 \%$ destes casos foram atribuídos diretamente à AIDS (VALL MAYANS et al. 1997).

A OMS estima que 10,7 milhões de pessoas estejam co-infectadas com o Mycobacterium tuberculosis e HIV ( $0,18 \%$ da população mundial) (DYE et al. 1999). Em 2000, $11 \%$ dos casos novos de TB em adultos (612 mil) ocorreram em pacientes infectados pelo HIV e $9 \%$ dos novos casos foram atribuídos diretamente a infecção pelo HIV (CORBETT et al. 2003). 
No Brasil, percentuais muito diversos têm sido observados entre as Unidades Federadas: maiores nas do sul e do sudeste e menores nas das outras regiões (HIJJAR et al.2001).

No Estado de São Paulo, a co-infeção HIV/TB aumentou na década de 1990 até atingir cerca de $20 \%$ do total de casos de tuberculose em 1997. Desde então, parece estar diminuindo lentamente (SECRETARIA DE ESTADO DA SAÚDE 2000).

A tuberculose interfere na evolução da AIDS, aumentando a letalidade pela própria doença ou diminuição da sobrevida, por contribuir para o agravamento da imunodeficiência (WHALEN et al. 1995; WHALEN et al. 2000). A progressão mais rápida da AIDS em pacientes com TB, quando comparados a controles HIV positivos com os mesmos níveis de CD4 e sem tuberculose, tem sido associada, entre outros fatores, a um aumento dos níveis séricos do fator de necrose tumoral (TNF $\alpha)$, com conseqüente ativação de células que apresentam infecção viral latente e aumento da replicação do HIV, verificando-se, na prática, aumento dos níveis plasmáticos de RNA viral (ELLNER 1997).

Nos Estados Unidos, entre 1992 e 1997, Centers for Disease Control and Prevention (CDC - Atlanta), registrou uma diminuição na incidência de TB (CDC 1998). Esta diminuição ocorreu principalmente na faixa etária entre 25-44 anos e em áreas com alta incidência de AIDS, sugerindo uma possível redução no HIV associado a TB. Embora esta redução seja atribuída 
principalmente a programas de controle da tuberculose, é possível que o uso de tratamento anti-retroviral combinado potente (HAART) possa também alterar a história natural da doença e das condições clínico-imunológicas associadas à AIDS (JONES et al. 1999).

Desde de a introdução em 1995. de inibidores de protease e inibidores não nucleosídeos da transcriptase reversa, tem sido observada uma diminuição na ocorrência de infecções oportunistas e na taxas de óbito por AIDS (MOCROFT et al. 1998, PALELLA et al. 1998, MCNAUGHTEN et al. 1999).

No entanto, estudos que analisam o impacto de HAART no desenvolvimento da doença tuberculose têm mostrado resultados variáveis.

Estudos recentes realizados em países desenvolvidos sugerem que o uso de HAART pode diminuir a incidência de TB associada ao HIV (KIRK et al. 1998, JONES et al. 1999, GIRARDI et al. 2000) e reduzir de 60 a $90 \%$ os óbitos por infecções oportunistas (MOCROFT et al. 1998). No entanto, em estudo realizado na Alemanha, não se encontrou redução significativa em uma coorte durante um período de 5 anos de uso de HAART. (BRODT et al. 1997).

Em um estudo de coorte na África do Sul, o uso de HAART reduziu o risco estimado de tuberculose em mais de $80 \%$ sendo o efeito protetor maior em pacientes sintomáticos e naquele com imunodeficiência avançada. (BADRI et al. 2002) 
SANTORO LOPES et al (2002) analisaram o impacto de HAART no Brasil, o primeiro país em desenvolvimento a garantir a terapia com antiretrovirais a todos os pacientes com imunodeficiência avançada. Neste estudo de coorte o uso de HAART foi associado a redução de $81 \%$ no risco de adoecimento por TB.

\section{4 -Resistência bacteriana às drogas}

A resistência do $M$. tuberculosis às drogas decorre de mutações espontâneas no cromossomo bacteriano que resultam na redução da susceptibilidade aos agentes tuberculostáticos (DAVID 1970).

A prevalência de mutantes resistentes em uma população bacilar livre da ação das drogas é extremamente baixa (DAVID 1970). A taxa de ocorrência de mutação espontânea para isoniazida (I) é de 1 em $10^{6}$ bacilos; para rifampicina (R), lem $10^{8}$; para etambutol (E), 1 em $10^{6}$; estreptomicina (S) $1 \mathrm{em} 10^{5}$ (SHIMAO 1987).

Como as drogas têm diferentes locais de ação e as mutações implicam em resistências fenotipicamente independentes torna-se extremamente remota a possibilidade de produção espontânea de multirresistência. (ISEMAN e MADSEN 1989) 
A probabilidade de que mutações espontâneas em um único bacilo resultem em resistência a mais de uma droga é obtida pela multiplicacão das freqüências individuais. A probabilidade de resistência a R e I é $10^{-8} \times 10^{-6}=$ $10^{14}$. Uma cavidade tuberculosa normalmente comporta de 10 milhões a 1 bilhão $\left(10^{7}\right.$ e $\left.10^{9}\right)$ de bacilos, então é teoricamente improvável que mutantes resistentes a duas ou três drogas ocorram espontaneamente em muitos pacientes (TOMAN 1979).

Embora sejam eventos quantitativamente raros, as mutações, quando ocorrem em populações bacterianas numerosas como, por exemplo, as intracavitárias e, sob pressão seletiva de uma única droga, podem levar ao predomínio de clones resistentes sobre os sensíveis, com conseqüente resistência ao tratamento instituído (MITCHISON 1984). Com uso de terapêutica combinada supera-se o problema da resistência mutacional. (ISEMAN e MADSEN 1989)

A base genética da resistência tem sido demonstrada recentemente. ZHANG et al. (1992) encontraram que mutações no gene katG estão associadas a resistência de $M$. tuberculosis à isoniazida. $\mathrm{O}$ gene $k a t G$ codifica a catalase-peroxidase envolvida na conversão da isoniazida em sua forma ativa na célula e observou-se que resistência a isoniazida está freqüentemente associada a falta de atividade da catalase. Notou-se que mutações ou deleções no gene $k a t G$ acometiam de $40 \%$ a $50 \%$ dos casos de resistência a isoniazida. Outros genes como inhA e kasA, que codificam enzimas na parede celular 
foram identificados como envolvidos na resistência à isoniazida (BANERJEE et al. 1994; MDULI et al. 1998). Quanto à resistência à rifampicina, esta decorre de mutações no gene $r p o \beta$ que codifica a RNA polimerase e em relação a estreptomicina, nos gens rrs ou rpsl (COLE e TELENTI 1995).

Define-se resistência primária como a presença de resistência a uma ou mais drogas antituberculose em um paciente que não havia recebido tratamento prévio com tuberculostático (VARELDZIS et al. 1994).

Resistência adquirida é definida como resistência a uma ou mais drogas antituberculose que aparece durante o tratamento, geralmente como resultado de não adesão ao regime de drogas recomendado ou prescrição falha (VARELDZIS et al. 1994).

Multirresistência é definida, internacionalmente, como resistência a isoniazida e rifampicina com ou sem relato de resistência às outras drogas (VARELDZIS et al. 1994). No Brasil, entretanto, tuberculose multirresistente às drogas é definida bacteriológicamente como resistência in vitro a pelo menos rifampicina e isoniazida e mais a uma ou mais das seguintes: drogas pirazinamida (P) e/ou etionamida e/ou etambutol e/ou estreptomicina (MINISTÉRIO DA SAÚDE 1997).

A resistência às drogas tuberculostáticas foi descrita logo após a introdução da estreptomicina no tratamento da TB (PYLE 1947). Entre os pacientes tratados com monoterapia por estreptomicina verificava-se redução da maior parte da população bacilar, sensível à droga administrada, com 
posterior predomínio da multiplicação de bacilos resistentes, resultando no fenômeno da negativação seguida de positividade nas baciloscopias de escarro ( PARSONS et al 1997).

$\mathrm{Na}$ década de 50 um ensaio clínico realizado pelo British Medical Council demonstrou a superioridade dos regimes que utilizavam a estreptomicina associada ao ácido para-aminosalicílico quando comparados aos resultados da monoterapia com estreptomicina, no tocante tanto às taxas de recaídas quanto à freqüência de desenvolvimento de resistência (MEDICAL RESEARCH COUNCIL 1952). Com a utilização em 1951 da isoniazida, a indicação do uso combinado de drogas foi consolidado para o tratamento da tuberculose (ISEMAN e MADSEN 1989).

$\mathrm{O}$ regime de tratamento de isoniazida com ácido para-aminosalicílico por 18 a 24 meses, mais estreptomicina durante os dois primeiros meses curou mais de $97 \%$ dos casos de $\mathrm{TB}$ com bacilos sensíveis às três drogas. No entanto, muitos países desenvolvidos não obtiveram sucessos com este esquema tratamento e, muitos casos novos que tinham bacilo sensíveis àquelas drogas desenvolveram resistência adquirida, alguns dos quais à isoniazida e estreptomicina (TOMAM 1979).

Em um levantamento realizado pela União Internacional Contra Tuberculose e Doenças Pulmonares (IUATLD) em 17 países no final da década de 50, foi encontrada resistência a estreptomicina em $3,7 \%$ dos casos, a isoniazida em $3 \%$ e às duas drogas em $1 \%$ dos casos (CROFTON 1960). 
No início dos anos 70, a rifampicina foi introduzida no tratamento da TB. Em diferentes países, estudos clínicos que avaliavam esquemas duplos, constituídos por isoniazida associada a diferentes drogas (R, S, E ou PAS) verificaram ser a rifampicina muito eficaz na prevenção da resistência à isoniazida, eficácia também demonstrada no tratamento dos casos resistentes a esta droga (MITCHISON e DICKINSON 1978; FOX 1978).

O problema da resistência diminuiu em muitos países desenvolvidos nos anos 60 e 70. Este decréscimo foi atribuído, em parte, ao tratamento supervisionado em sanatórios bem como ao advento da rifampicina e desenvolvimento da quimioterapia de curta duração (KOCHI et al. 1993).

A resistência às drogas antituberculose foi reconhecida como problema clínico esporádico entre os anos 60 e 80 e pouca atenção foi dada ao problema por pesquisadores e autoridades de saúde pública. (NACHEGA e CHAISSON 2003)

De 1975 a 1982 um inquérito realizado pelo CDC em 20 laboratórios nos Estados Unidos mostrou que a resistência primária a uma ou mais drogas era de $6,9 \%$. Neste período houve declínio na tendência de resistência de $13 \%$ a 7\% entre as amostras analisadas (WOLINSKY 1993). Verificou-se também diferença nas prevalências segundo raça ou etnia (Asiáticos, 14,8\%; Hispânicos, 11,8\%, Negros, 6,1\%; brancos não-hispânicos, 4,9\% e Americanos, 4,1\%) e distribuição geográfica (SNIDER et al. 1991). 
Em outro inquérito realizado de março de 1982 a março de 1986, o CDC avaliou a resistência primária e adquirida em 4.224 pacientes. A resistência primária foi encontrada em $9 \%$ das amostras, taxa maior que a do período anterior. Este estudo mostrou também diferença entre raças ou grupos étnicos e localização geográfica, com um declínio na tendência de resistência primária, mas não na adquirida (SNIDER et al. 1991).

Devido a diferenças metodológicas entre os inquéritos, diminuição nos recursos e outras prioridades de estudo, o $\mathrm{CDC}$ interrompeu inquéritos sobre resistência às drogas antituberculose em 1986 (SNIDER et al. 1991).

No Brasil, a utilização de drogas em maior escala se iniciou em 1946 no tratamento com estreptomicina, seguida em 1948 pelo ácido paraaminosalicílico e em 1952 pela isoniazida. A partir de 1948 já se utilizava a associação S/PAS e, nos anos 50, também as associações I/S e H/PAS (ROSEMBERG et al. 1967).

Em um estudo realizado pelo Laboratório Central de Tuberculose do Rio de Janeiro nos anos de 1958 e 1959, em 66\% das amostras analisadas verificava-se resistência a duas ou três drogas (I/S/PAS). Na década seguinte utilizou-se o esquema de tratamento de 18 meses de duração com associação das três drogas existentes. Acredita-se que este esquema tenha contribuído para redução das taxas de resistência , pois no mesmo laboratório verificou-se em 1966 resistência a duas ou três drogas em $28 \%$ das amostras. Quanto a 
resistência primária verificou-se, no total de amostras do período de 1960 a 1966, 8,2\% de resistência à estreptomicina, $6,0 \%$ à isoniazida e $0,8 \%$ ao PAS. (MAGARÃO et al. 1967)

MELO et al.(1996), avaliaram a resistência primária às drogas na década de 80 no Instituto Clemente Ferreira, referência ambulatorial para TB na Grande São Paulo. Os autores comparam os resultados encontrados aos relatados em estudos que foram realizados no mesmo Instituto nas décadas de 60 e 70. Observou-se um decréscimo progressivo entre as décadas. A resistência primária caiu de $17,2 \%(70 / 706)$ na década de 60 , para $9,6 \%$ (37/387) na década de 70 e $7,4 \%(34 / 458)$ na década de 80 . Houve também redução na resistência à isoniazida e estreptomicina de $11,1 \%$ e $10,8 \%$ na década de 60 , para $6,5 \%$ e $5,4 \%$ na de 70 , para $3,9 \%$ e $3,7 \%$ na de 80 , respectivamente. A resistência primária à rifampicina testada apenas em $70 \mathrm{e}$ 80, foi baixa, com aumento estatisticamente significante de 0,3 para $1,1 \%$. Esta redução provavelmente decorre da melhor organização do programa de controle da doença e a introdução de drogas mais potentes como a rifampicina (MELO et.al 1996). O esquema de tratamento de curta duração (6 meses) utilizando a rifampicina foi introduzido no Brasil em 1979 (RUFFINONETTO, 2002).

Um estudo realizado no Instituto Adolfo Lutz de São Paulo (IAL) entre os anos de 1986 e 1990 mostrou que a taxa de resistência primária foi de 16,54\%. A maior taxa de resistência, por droga isolada, foi para 
estreptomicina $(4,34 \%)$, seguida da isoniazida $(2,76 \%)$, rifampicina $(0,79 \%)$ e pirazinamida $(0,39 \%)$. A taxa de resistência adquirida nas amostras examinadas foi de $47,45 \%$, sendo maior para a isoniazida $(6,93 \%)$ seguida pela estreptomicina $(3,47 \%)$, pirazimanida $(1,56 \%)$ e rifampicina $(1,49 \%)$. O índice de resistência à associação isoniazida e rifampicina foi de $8,42 \%$ (SILVA et al. 1992)

Desde 1988, tem ocorrido aumento no número de casos de resistência bacteriana às drogas tuberculostáticas, inclusive nos países desenvolvidos (SCHOWOEBEL et al. 1998).

$\mathrm{O}$ aumento do número de linhagens resistentes tem causado enorme preocupação, pois contribui para aumentar a proporção de mortes por TB (SNIDER e ROPER 1992), dificulta o tratamento e a prevenção da doença (ROSSETI et al. 2002).

No início dos anos 90, vários estudos relataram aumento do número de casos de bacilos multirresistentes nos Estados Unidos.(SHAFER et al 1991; MONNO et al. 1991; CDC 1991)

FRIEDEN et al.(1993), coletaram informações de todos os pacientes com resultado de cultura positiva para M.tuberculosis na cidade de Nova Iorque em abril de 1991. Em 90\% destes pacientes (466) foi realizado teste de sensibilidade às drogas. Resistência a uma ou mais drogas foi encontrada em $33 \%$ dos casos e $19 \%$ apresentou resistência a isoniazida e rifampicina. Entre 
os pacientes previamente tratados, $44 \%$ apresentaram resistência a uma ou mais drogas e $30 \%$ resistência a isoniazida e rifampicina. A proporção de resistência a uma ou mais drogas entre os que não haviam sido tratados foi de $23 \%$. Ao compararem estes dados ao de outro estudo realizado entre 1982 e 1984, os autores observaram um aumento de $130 \%$ na resistência a uma ou mais drogas entre os pacientes que nunca receberam tratamento.

Neste período ocorreram os surtos de transmissão nosocomial de tuberculose multirresistente (TBMR) que acometeram até 1992 cerca de 300 indivíduos principalmente em Nova Iorque e na Flórida (KENT 1993). Estes surtos foram caracterizados pela alta prevalência em indivíduos HIV positivos (20\% a $100 \%$ dos casos), altas taxas $(72 \%$ a $89 \%)$, curto intervalo entre o diagnóstico de TB e o óbito (4 a 16 semanas) e transmissão de TBMR a profissionais de saúde e trabalhadores de casas de apoio. Pelo menos 17 profissionais desenvolveram TBMR ativa. Na maioria dos hospitais havia demora no diagnóstico de TB e na identificação da resistência às drogas; falta de medidas de isolamento adequadas e aglutinação de grande número de pacientes altamente suscetíveis (CDC 1993).

Estudo tipo caso-controle realizado em um hospital de Nova Iorque entre pacientes com AIDS encontrou os seguintes fatores de risco associados a TBMR: tempo de evolução da AIDS no momento do diagnóstico e hospitalização seis meses antes do diagnóstico de TBMR. Ao realizar teste tuberculínico (PPD - Derivado Proteico Purificado) entre os funcionários do 
hospital durante o surto de TBMR foi observada conversão em $18 \%$ dos trabalhadores com teste previamente negativo, sendo que um trabalhador desenvolveu tuberculose resistente a isoniazida e estreptomicina (EDLIN et al. 1992).

Um estudo realizado em um hospital de Miami - Flórida, de janeiro de 1988 a janeiro de 1990 comparou 25 pacientes HIV positivos com TBMR e 62 HIV positivos com tuberculose sensível (TBS); os autores demonstraram associação estatistcamente significante entre resistência às drogas e ocorrência de infecções oportunistas antes do início da TB, com uma letalidade maior neste grupo. Entre os trabalhadores do hospital, a taxa de conversão do teste tuberculínico foi maior entre os que trabalhavam nas alas e ambulatório para pacientes com HIV quando comparados aos que trabalhavam na ala de cirurgia de tórax (BECK-SAGUÉ et al. 1992).

Estes surtos nosocomiais levantaram várias questões sobre a epidemiologia da TB resistente nos Estados Unidos. Um inquérito nacional sobre a resistência às drogas entre todos os pacientes com TB foi realizado de janeiro a março de 1991. Dos 3.313 casos investigados, 14,2\% apresentaram resistência a pelo menos uma droga. Resistência a isoniazida e rifampicina foi encontrada em $3,4 \%$ dos casos. O risco de desenvolver TBMR foi 10 a 50 vezes maior nas minorias étnicas e raciais quando comparados aos brancos não-hispânicos. Não foram avaliados alguns fatores de risco como a presença de infecção pelo HIV. Mais da metade dos casos de TBMR $(61,4 \%)$ ocorreram 
na cidade de Nova Iorque e os Estados com maior proporção de casos foram Nova Iorque $(12,9 \%)$, Nova Jersey $(6,6 \%)$ e Flórida $(4,95)$ (BLOCH et al. 1994).

A partir de 1993 houve diminuição dos casos de TB e de TBMR em Nova Iorque (FRIEDMAN et al.1995) e nos Estados Unidos, em decorrência principalmente das medidas voltadas para assegurar maior adesão ao tratamento e medidas para prevenir a transmissão nosocomial em hospitais, consultórios médicos, albergues e casas de apoio (CDC 1994).

Surtos de TBMR semelhantes aos que ocorreram nos EUA também foram descritos em Portugal (HANNAN et al 2001), Itália (MORO et al. 1998) e Argentina (RITACCO et al. 1997). Nestes países a análise por RFLP (restriction fragment length polymorfism) das cepas isoladas confirmaram a transmissão nosocomial.

Em 1997 a OMS considerava que havia poucas evidências rigorosamente comprovadas de que a resistência estivesse se tornando uma crescente ameaça à efetividade dos programas nacionais de controle da TB, mas alertava para o fato de que os dados disponíveis indicavam níveis altos e crescentes de resistência em várias partes do mundo (WHO 1997).

Até recentemente não haviam dados disponíveis sobre a distribuição da resistência às drogas mundialmente (PABLO-MENDEZ et al. 2002). COHN et. al (1997) ressaltaram os fatores que dificultavam tanto a avaliação quanto as comparações sobre o problema da resistência: a falta de padronização e de 
recursos para realização de exames laboratoriais, a escassez de estudos com ampla e representativa amostragem de casos e a escassez de estudos longitudinais, que permitissem avaliar tendência dos níveis de resistência em diferentes períodos.

Em 1994, a OMS e IUATLD lançaram o Projeto Global de Vigilância da Resistência às Drogas Antituberculose. Os resultados de um inquérito mundial foram publicados em 1997. (WHO 1997a). Este inquérito foi realizado de 1994 a 1997 em 35 países dos 5 continentes com uma amostra de 50 mil pacientes. Resistência a drogas como isoniazida e estreptomicina foi encontrada em todos os países. No total, $9,9 \%$ dos pacientes tinham resistência a pelo menos uma droga e $1 \%$ eram TBMR. Observou-se existência de focos de TBMR primária preocupantes na Estônia com taxa de 14\%, na Latvia e na Rússia (Ivanovo e Tomsk) com percentuais próximos a 10\%. Outros países como Irã, Moçambique, Peru e Argentina apresentaram percentuais de acima 3\%. No Brasil, observou-se resistência primária de 1,1\%, resistência adquirida de $8,2 \%$ e resistência combinada de $2,2 \%$, taxas consideradas baixas (HIJJAR et al.2001). Este estudo não avaliou tendência na prevalência de resistência, visto que para algumas regiões os dados disponíveis eram de apenas um ano. (WHO 2000)

No segundo inquérito, publicado em abril de 2000, foram avaliados dados de 72 países e pode-se analisar a tendência da resistência em alguns deles. Entre os casos de TB que nunca haviam sido tratados, a prevalência da 
resistência a pelo menos uma droga variou de $1,7 \%$ no Uruguai a $36,9 \%$ na Estônia (média de 10,7\%). A TBMR entre os que não haviam sido tratados variou de $0 \%$ em oito localidades a $14,1 \%$ na Estônia (média de 1\%). Altas prevalência de TBMR foram observadas em Província Henan na China $(10,8 \%)$, Ivanovo na Federação Russa $(9 \%)$, Latvia ( $9 \%)$, Tomsk na Federação Russa $(6,5 \%)$ e o Irã $(5 \%)$. Um aumento estatisticamente significante na prevalência de TBMR foi observado na Estônia de 10,2\% em 1994 para 14,1\% em 1998. Em países como França (0,5\% em 1994 e 0\% em 1998) e Estados Unidos (1,6\% em 1994 e 1,2\% em 1998) houve diminuição da prevalência de TBMR. (WHO 2000)

Entre os pacientes previamente tratados, a resistência a pelo menos uma droga variou de $0 \%$ na Finlândia a $94 \%$ no Uruguai (média de $23,3 \%$ ). TBMR variou de $0 \%$ em quatro localidades a $48,2 \%$ no Irã (média de $9,3 \%$ ). Uma diminuição estatisticamente significante na prevalência de resistência a pelo menos uma droga foi observada em Cuba, Inglaterra, Peru e Coréia. Quanto a prevalência de TBMR houve aumento na Estônia de 19,2\% em 1994 a 37,8\% em 1998 (WHO 2000).

Dentre os fatores de risco para casos de bacilos resistentes destacam-se:

- Deterioração das ações dos programas de controle da TB (BRUDNEY e DOBKIN 1991; FRIEDEN et al. 1993); 
- Prescrição inadequada e falhas, tanto no suprimento de medicamentos quanto nas ações que assegurem a aderência do paciente ao tratamento (O'BRIEN 1994; REICHMAN 1994; ROSSETTI et al. 2002);

- História de tratamento anterior de tuberculose (ISEMAN e MADSEN 1989; BRUDNEY e DOBKIN 1991; FRIEDEN et al. 1993; SALOMON et al. 1994; WHO 2000; ESPINAL et al 2001);

Embora casos de resistência às drogas entre pacientes co-infectados tenha sido muito bem documentada nos EUA, a predisposição destes pacientes para desenvolver tuberculose resistente ainda tem sido motivo de controvérsia na literatura (SPELLMAN et al. 1998).

Diversos estudos têm demonstrado que a co-infecção do $M$. Tuberculosis com o HIV é um fator de risco independente associado a tuberculose resistente (PITCHENIK et al. 1984; GORDIN et al. 1996; FRIEDEN et al. 1996; LIU et al. 1998). Outros autores não encontraram associação entre HIV e tuberculose resistente (COHN et al. 1997; ESPINAL et al. 2001).

Ao comparar a prevalência de tuberculose resistente entre pacientes HIV positivos e negativos, SPELLMAN et al (1998) concluíram que a infecção pelo HIV não é fator de risco para desenvolvimento de resistência. Segundo os autores, os pacientes HIV positivos que se tornam infectados por TB têm uma maior probabilidade de desenvolver doença ativa e portanto coinfecção não aumentaria o risco de resistência a drogas; apenas o problema do 
aumento da resistência às drogas poderia se manifestar mais cedo em pacientes infectados pelo HIV. Assim, o padrão de resistência de indivíduos HIV positivos refletiria o padrão de resistência atual da comunidade. Inversamente, a doença ocorrendo em HIV negativos refletiria o padrão de resistência no momento da infecção, que provavelmente teria ocorrido anos ou décadas antes.

Outro estudo realizado nos EUA avaliou o impacto do HIV na TB resistente no período de janeiro de 1992 a junho de 1994. A infeção pelo HIV mostrou-se associada a TB resistente independente de raça, tratamento anterior de tuberculose e local de residência (GORDIN et al 1996).

LIU et al. (1998) ao avaliarem fatores de risco para TB resistente encontraram uma forte associação entre infecção pelo HIV e TBMR independente da idade, sexo, uso de drogas injetáveis e alcoolismo.

Alguns estudos têm sugerido que a infecção pelo HIV parece favorecer a resistência adquirida (DYLEWSKI e THIBERT 1990; SMALL et al 1991). A resistência adquirida em pacientes HIV positivos está ocassionalmente mais associada a rifampicina do que a isoniazida. (LUFTEY et al. 1996; MARCH et al. 1997; SANDMAN et al 1999).

BRADFORD et al. (1996), avaliando os resultados dos testes de sensibilidade de 2.612 caos de TB notificados entre 1985 e 1994, na cidade de São Francisco (EUA), verificaram um aumento da incidência de resistência adquirida naquele período e, em um estudo tipo caso-controle, comparando 14 
casos, todos com resistência adquirida confirmada por análise de RFLP e 56 sensíveis, verificaram associação entre resistência e três fatores de risco considerados independentes: não aderência à terapêutica, AIDS e sintomas gastro-intestinais. Seis dos 14 pacientes resistentes, todos com diagnóstico de AIDS, apresentaram monorresistência a rifampicina.

Algumas hipóteses, além de falhas no tratamento, têm sido relacionadas a resistência adquirida e HIV positivo. A reinfecção exógena com um novo bacilo resistente ao $M$. tuberculosis, durante ou depois do tratamento da tuberculose sensível, têm sido descrita em pacientes com avançada imunodeficiência causada pelo HIV (SMALL et al. 1993). A interação entre drogas anti-tuberculose e certos medicamentos utilizados para tratamentos de doenças relacionadas ao HIV pode interferir na meia-vida da isoniazida e rifampicina. (GRANGE et al. 1994)

A má absorção de drogas em pacientes HIV positivos também parece estar relacionada a resistência adquirida (PELOQUIM et al. 1993; PATEL et al. 1995; BRADFORD et al. 1996).

Quanto ao problema da resistência às drogas antituberculose em pacientes HIV positivos no Brasil, há relatos de casos isolados e outros com casuísticas limitadas, não tendo se caracterizado em definitivo a ocorrência de maiores índices de resistência em pacientes com TB soropositivos para o HIV. 
No Rio de Janeiro, WERNECK-BARROSO et al. (1995) registraram resistência primária em 4 de 20 casos de TB em pacientes HIV positivos. Destes pacientes dois apresentaram resistência à isoniazida, um caso resistência combinada a isoniazida e estreptomicina e um caso resistente a todas as drogas exceto pirazinamida. Em outro estudo no Rio de Janeiro, MACHADO et al. (1994), ao avaliarem o perfil de resistência em 48 pacientes HIV positivos, relataram as seguintes taxas de resistência: $14,8 \%$ para isoniazida e $12,5 \%$ para associação isoniazida e rifampicina.

Em um estudo que avalia fatores de risco para ocorrência de TB resistente em pacientes HIV positivo, realizado em São Paulo houve correlação entre resistência e tratamento prévio com tuberculostático e tempo de evolução de AIDS. As variáveis consumo de bebidas alcoólicas, idade, sexo e situação de domicilio (com ou sem residência) não mostraram estar associadas a TB resistente. (PINTO 1998).

Em um estudo transversal realizado em um hospital de referência para tratamento de HIV/AIDS de Santa Catarina, no período de outubro de 1995 a setembro de 1996, constatou-se que o paciente que referiu mais de duas internações prévias tendeu, de modo significativo, a apresentar cepa resistente às drogas anti-TB. Esta associação não se observou com relação a tempo de soropositividade e tratamento anterior de TB (GOMES et al. 2000). 


\section{5 - Justificativa}

A Baixada Santista apresenta uma das maiores prevalências de TB e incidência de AIDS do Estado de São Paulo, o que propicia a ocorrência de co-infecção, sendo região prioritária para a Secretaria de Estado de Saúde. A região conta com serviços de saúde organizados e especializados, o que favorece a realização de pesquisas na área.

A relevância da resistência a drogas para o controle da $\mathrm{TB}$, o impacto da infecção pelo HIV na incidência da TB e a importância destas doenças na Baixada Santista - SP justificam a realização deste estudo. 


\section{2 - Objetivos:}

Identificar fatores associados a resistência às drogas anti-tuberculose e o padrão de resistência do $M$. tuberculosis nos indivíduos HIV positivos dos seguintes municípios da Baixada Santista -SP: Santos, São Vicente, Cubatão, Praia Grande e Guarujá; no período de janeiro de 1993 a março de 2003.

\section{Objetivos específicos}

1- Com relação aos fatores associados a resistência ao tratamento Identificar possíveis relações entre os casos de tuberculose resistente e os seguintes fatores de risco: idade, sexo, ingestão de álcool, tratamento anterior com tuberculostáticos, uso de anti-retrovirais, tempo de evolução do HIV, internação hospitalar prévia a tuberculose, moradia, ser presidiário e estágio evolutivo do HIV+ (contagem de células CD4 e carga viral).

2- Com relação ao padrão de resistência bacteriana

Calcular a freqüência de resistência primária e resistência adquirida

Calcular a freqüência de resistência a uma ou mais drogas 


\section{3 - Material e Métodos}

\section{1- População}

A população de estudo foi selecionada a partir de levantamento junto aos livros de registro de amostras de escarro do setor de Microbiologia do Instituto Adolfo Lutz de Santos (IAL-Santos) e de São Paulo (IAL-SP).

Foram selecionados todos os pacientes que apresentaram cultura positiva e cujas cepas isoladas e identificadas como $M$. tuberculosis foram submetidas a teste de sensibilidade aos seguintes tuberculostáticos: Rifampicina, Isoniazida e Pirazinamida, Etambutol e Estreptomicina.

O período considerado foi de 01 de janeiro de 1993 a 31 de março de 2003. A data inicial foi escolhida tendo como base a disponibilidade de dados e exames de sensibilidade.

Foram considerados elegíveis os pacientes maiores de 13 anos de idade que apresentavam evidências de infecção pelo HIV e estavam matriculados em uma das seguintes unidades de saúde:

- Centro de Referência em Aids de Santos (CRAIDS);

- Serviço de Atendimento Especializado de São Vicente (SAE-SV);

- Vigilância Sanitária de Cubatão;

- Hospital Dia William da Rocha do Guarujá (HDWR);

- Serviço de Atendimento Especializado de Praia Grande (SAE-PG) 
Para obtenção dos dados laboratoriais, epidemiológicos e clínicos dos pacientes foi realizada pesquisa retrospectiva de seus prontuários por meio de formulário padronizado (vide ANEXO 1).

As informações sobre data e causas de óbito foram obtidas nos serviços de Vigilância Epidemiológica de cada município e na Fundação Sistema Estadual de Análise de Dados (SEADE) do Estado de São Paulo .

\section{2- Exames de laboratório}

Os exames de baciloscopia de escarro para diagnóstico etiológico e controle de tratamento de TB foram solicitados nos laboratórios de cada município em procedimentos de rotina e realizados por meio da coloração de Ziehl-Nielsen. A identificação das espécies de micobactérias e os testes de avaliação da sensibilidade às drogas tuberculostáticas foram realizadas no Setor de Microbiologia do IAL-Santos e IAL-SP.

As amostras de escarro foram submetidas a descontaminação pelo método de Petroff, semeadas em meio de Löwenstein-Jensen e incubadas a $37^{\circ} \mathrm{C}$. As micobactérias isoladas foram identificadas como Mycobacterium tuberculosis por meio de suas propriedades bioquímicas. As micobactérias de crescimento lento (superior a sete dias), produtoras de niacina, redutoras de nitrato, sensíveis ao ácido para nitrobenzóico e resistentes ao ácido 2- 
tiofenocarboxílico caracterizaram o Mycobacterium tuberculosis (KANTOR 1988).

Até julho de 1994, os testes de avaliação de sensibilidade às drogas foram realizados pelo Método das Proporções. As drogas examinadas e as concentrações críticas utilizadas foram: isoniazida $0,2 \mathrm{mcg} / \mathrm{ml}$; rifampicina 40,0 $\mathrm{mcg} / \mathrm{ml}$; pirazinamida (P) $200,0 \mathrm{mcg} / \mathrm{ml}$; etambutol $2,0 \mathrm{mcg} / \mathrm{ml}$; estreptomicina $4,0 \mathrm{mcg} / \mathrm{ml}$. As soluções estoques de cada droga foram preparadas na concentração de $10.000 \mathrm{mcg} / \mathrm{ml}$ e conservadas a $-20^{\circ} \mathrm{C}$ (CANETTI et al. 1969).

A partir de agosto de 1994 os teses foram realizados pelo Método da Razão de Resistência. Foram consideradas resistentes à $\mathrm{H}, \mathrm{R}, \mathrm{S}$ ou $\mathrm{E}$ as cepas de Mycobacterium tuberculosis que apresentaram crescimento em tubos contendo drogas em concentrações que, em relação às concentrações de drogas dos tubos controle, resultaram em razões iguais ou maiores que 4:1. Foram consideradas resistentes à $\mathrm{P}$ as cepas que apresentaram crescimento em tubos com esta drogas na concentração de 200 ug/ml (COLLINS et al 1997).

Os exames de contagem de células CD4/CD8 e carga viral do HIV foram realizados pelo laboratório do CRAIDS até o ano de 1997. A partir de 1998, estes exames foram realizados pelo IAL-Santos no Setor de Sorologia, com exceção dos exames solicitados pelo CRAIDS que continuaram sendo realizados no próprio laboratório da unidade de saúde. 


\section{3 -Variáveis Estudadas}

O desenho do estudo realizado obedece aos princípios básicos de um estudo transversal, considerando a ocorrência de resistência como variável dependente e como variáveis independentes foram considerados:

- Idade do paciente no momento do diagnóstico de TB;

- Sexo;

- Com moradia: foram considerados como positivos os casos em que constava no prontuário endereço domiciliar definido e foram considerados como negativos os casos em que constavam referências de ser o paciente "morador de rua".

- Presidiário: foram considerados positivos os casos que constava no prontuário ter sido o paciente detento em penitenciárias, cadeias ou presídios antes do diagnóstico de TB.

- Consumo de bebidas alcoólicas: foram registrados como positivos os casos em que, em consulta médica, psicológica ou com o Serviço Social, havia referência a consumo de bebidas alcoólicas, ainda que sem especificação da quantidade ou regularidade; foram considerados como negativos os casos em que constavam no prontuário as anotações referentes a hábito: "nega alcoolismo", "etilista social"; 
- Usuário de drogas injetávéis (UDI): foram considerados como positivos os casos em que constava no prontuário referência a uso de drogas injetáveis ainda que tenha sido apenas uma vez. Foram considerados negativos os casos em que constavam no prontuário anotações referentes a hábito: "nega uso de drogas injetáveis";

- Uso de medicamento anti-retroviral (ARV): foram considerados positivos os casos com registro de prescrição de qualquer medicamento anti-retroviral por um período mínimo de 1 mês antes do diagnóstico de TB;

- Uso de medicação anti-retroviral combinada potente (HAART): foram considerados positivos os casos com registro de prescrição de HAART por um período mínimo de 1 mês antes do diagnóstico de TB. Foi considerado HAART esquemas que possuíam 2 medicamentos inibidores da transcriptase reversa análogo de nucleosídeo e 1 ou 2 inibidores de protease ou 1 inibidor da transcriptase reversa não análogo de nucleosídeo.

- CD4 anterior ao tratamento: o exame de contagem de células CD4 imediatamente anterior ao início do tratamento de tuberculose foi considerado como marcador da situação imunológica do paciente no momento próximo ao diagnóstico;

- Carga viral anterior ao tratamento: o exame de contagem de replicação do vírus HIV imediatamente anterior ao início do 
tratamento de tuberculose foi considerado como marcador da situação imunológica do paciente no momento próximo ao diagnóstico;

- Hospitalização prévia a TB: foram considerados positivos os casos em que haviam no prontuários registros de internação antes do diagnóstico de tuberculose e posterior ao diagnóstico de HIV+. Foram considerados negativos os casos em que havia no prontuário registro de internação após o diagnóstico de TB;

- Antecedentes de tratamento com drogas tuberculostáticas: foram anotados como positivos os casos em que foi referido tratamento anterior por período igual ou superior a um mês. Foram anotados como negativos os casos em que constavam no prontuário a anotação "nega TB".

- Tempo de evolução do HIV: para análise do tempo de soropositivdade para o HIV no momento do diagnóstico de TB esta variável foi analisada em dois estratos em relação ao tempo: até 4 anos e mais de 5 anos de soropositividade. 


\section{4- Definições:}

Tuberculose resistente, tuberculose multirresistente, resistência adquirida e resistência primária foram classificadas conforme critérios recomendados pela OMS (VARELDZIS et al 1994).

1- Tuberculose resistente: casos de tuberculose resistente a uma ou mais drogas.

2- Tuberculose multirresistente: resistência a pelo menos Isoniazida e Rifampicina.

3- Resistência primária: presença de resistência a uma ou mais drogas em pacientes que não haviam recebido medicamentos antituberculose anteriormente.

4- Resistência adquirida: presença de resistência a uma ou mais drogas em pacientes previamente tratados com drogas antituberculose, por um período mínimo de 1 mês.

5- Resistência indeterminada: presença de resistência a uma ou mais drogas em pacientes sem informação em prontuário sobre tratamento anterior com tuberculostáticos 


\section{5- Análise estatística}

Para entrada dos dados em computador, utilizou-se o programa Epi Info na versão 6.04 (DEAN et al. 1997). Para investigar valores improváveis/extremos, produziram-se distribuições de freqüência das variáveis. Procedeu-se ao cruzamento de algumas variáveis para avaliar consistência e coerência dos dados obtidos. Quando havia dúvidas, o instrumento de coleta era consultado para possível correção.

Inicialmente foi realizada uma análise descritiva segundo as principais variáveis investigadas. As variáveis contagem de carga viral e ser ou ter sido presidiário apresentaram mais de $50 \%$ de casos sem informação e foram excluídas da análise.

Para verificar prováveis associações entre os diversos fatores e o desenvolvimento tuberculose resistente entre os pacientes HIV positivos, foi calculado o odds ratio (OR) com intervalo de $95 \%$ de confiança, considerando a existência ou não de tuberculose resistente como variável dependente e as várias exposições como variáveis independentes.

A avaliação inicial foi realizada por meio de análise univariada e pela análise estratificada utilizando o programa Epi info 6.04 e STATA (STATACORP 1995). Para variáveis ordinais agrupadas foi calculado o $\chi^{2}$ para tendência (MANTEL 1963). 
Para análise multivariada utilizou-se a regressão logística não condicional (HOSMER e LEMESHOW 1989). Inicialmente foram incluídas no modelo todas as variáveis selecionadas na análise univariada e aquelas que não contribuíram para a explicação da presença da resistência foram excluídas, uma a uma (backward elimination) do modelo inicial. A significância estatística foi avaliada usando o teste de razão de verossimilhança comparando o "deviance" ((-2ln(verossimilhança)) entre o modelo com e sem a variável. Esta estatística obedece a uma distribuição $\chi^{2}$ com número de graus de liberdade igual à diferença entre os graus de liberdade entre os dois modelos.

Para controlar o possível efeito confundidor de algumas variáveis, foi realizada análise estratificada pela técnica de MantelHaenzsel (ROTHMAN e GREENLAND 1998). Nesta análise foram incluídas as variáveis que se associaram significativamente à resistência ao $M$. tuberculosis na análise univariada.

Este estudo foi aprovado pelo Comitê de Ética em Pesquisa da Faculdade de Saúde Pública da Universidade de São Paulo -COEP (Of. COEP/32/03) em 11/02/2003. 


\section{4- Resultados:}

No período de janeiro de 1993 a março de 2003 foram obtidas 343 culturas positivas cujas cepas foram isoladas e identificadas como M.tuberculosis com subseqüente avaliação da sensibilidade. Destes, 42 $(12,2 \%)$ foram excluídos do estudo visto que em dois casos não foi encontrado resultado de exame anti-HIV, em seis casos não havia registro de consultas no prontuário e em 34 casos o prontuário não foi encontrado. Foram estudados portanto 301 casos.

\section{1-Características da população estudada}

4.1.1-Distribuição da população de estudo segundo município de atendimento

Dos casos analisados $243(80,7 \%)$ estavam matriculados no CRAIDSSantos, $19(6,3 \%)$ no SAE de São Vicente, $16(5,3 \%)$ no Núcleo de Vigilância à Saúde de Cubatão , 15 (5,0\%) no HDWR-Guarujá e 8 (2,7\%) no SAE de Praia Grande.

4.1.2- Distribuição dos casos segundo sexo e idade 
Dos 301 casos revistos $69,1 \%$ (208 casos) eram do sexo masculino. Considerando a distribuição etária, os resultados mostram uma população com idade média de 35,5 anos (desvio padrão de 8,19 anos), sendo o mais jovem com 20 anos e o mais velho com 70 anos de idade.

4.1.3-Distribuição dos casos segundo forma clínica da tuberculose

Dos casos analisados, $273(90,7 \%)$ apresentaram somente a forma clínica pulmonar. Em 9,3\% dos casos foi diagnosticada TB disseminada embora nos prontuários destes casos não tenham sido encontrados exames que comprovassem esta forma de tuberculose.

\subsection{4- Distribuição segundo estágio evolutivo da infecção pelo HIV}

A Tabela 1 mostra a distribuição dos casos segundo contagem absoluta de linfócitos $\mathrm{CD} 4+$ no sangue periférico no momento imediatamente anterior ao diagnóstico de TB. A imunodeficiência avançada (contagem de CD4+ abaixo de $200 / \mathrm{mm}^{3}$ ) esteve presente em $41,9 \%$ dos casos. 
TABELA 1. Distribuição dos casos de TB/HIV segundo contagem de linfócitos CD4+ no sangue periférico, Baixada Santista -1993-2003

\begin{tabular}{lc}
\hline Contagem de linfócitos CD4+/ $\mathrm{mm}^{3}$ & $\mathrm{~N}^{\circ} .(\%)$ \\
\hline Menos de 200 & $126(41,9)$ \\
$200-499$ & $75(24,9)$ \\
500 ou mais & $26(8,6)$ \\
Ignorado & $74(24,6)$ \\
\hline Total & $301(100,0)$ \\
\hline
\end{tabular}

4.1.5- Tempo de evolução do HIV na data do diagnóstico de tuberculose

O tempo decorrido entre o diagnóstico de HIV e o de tuberculose variou de 3 a 5.314 dias sendo de 1.349 dias em média, com mediana de 1.122 dias. Dois casos que tinham data de exames de HIV posteriores ao diagnóstico de TB foram excluídos desta análise.

A Tabela 2 mostra a distribuição dos casos em relação ao tempo (em anos) de evolução do HIV e ao diagnóstico de tuberculose. Dos 299 casos analisados, $207(69,2 \%)$ pacientes desenvolveram tuberculose até 4 anos após o diagnóstico de HIV. 
TABELA 2- Distribuição dos casos de TB/HIV segundo tempo (em anos) de evolução do HIV na data do diagnótico de TB, Baixada Santista -1993-2003

\begin{tabular}{lcc}
\hline $\begin{array}{l}\text { Tempo de evolução do HIV } \\
\text { (em anos) }\end{array}$ & $\mathrm{N}^{\circ}$ de casos & $\%$ \\
\hline 0 a 4 & 207 & 69,2 \\
5 ou mais & 92 & 30,8 \\
\hline Total & 299 & 100,0 \\
\hline
\end{tabular}

4.1.6- Distribuição dos casos segundo uso de medicação anti-retroviral antes do diagnóstico de TB

Dos 301 casos avaliados, 19,3\% (58 casos) fizeram uso de algum tipo de medicamento anti-retroviral antes do diagnóstico de TB. O uso de HAART foi verificado em $25,6 \%$ do total de prontuários revistos (Tabela 3). Entre os pacientes em uso de HAART 52 (67,5\%) fizeram uso de esquema que continha inibidores de protease.

TABELA 3. Distribuição dos casos de TB/HIV segundo uso de $A R V^{*}$ ou

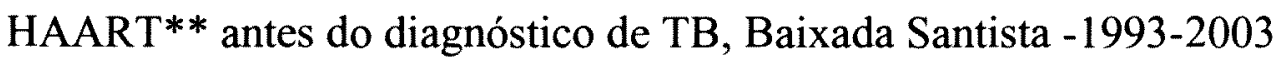

\begin{tabular}{lc}
\hline Tipo de medicação & $\mathrm{N}^{\circ} .(\%)$ \\
\hline ARV $^{*}$ & $58(19,3)$ \\
HAART** & $77(25,6)$ \\
Não fizeram uso & $166(55,1)$ \\
\hline Total & $301(100,0)$ \\
\hline ARV= medicamento anti-retroviral ${ }^{* *}$ HAART = tratamento anti-retroviral combinado potente
\end{tabular}


4.1.7 - Distribuição dos casos segundo antecedentes de consumo de bebidas alcoólicas, uso de drogas injetáveis e moradia

O consumo de bebidas alcoólicas foi referido em 107 (35,5\%) dos prontuários avaliados durante o seguimento nas unidades de saúde. $\mathrm{O}$ uso de drogas injetáveis foi referido em $40,5 \%$ dos casos $; 11,6 \%$ dos pacientes não tinham moradia. (Tabela 4)

TABELA 4. Distribuição dos casos de TB/HIV segundo condição de moradia, consumo de bebidas alcoólicas e uso de drogas injetáveis, Baixada Santista 1993-2003

\begin{tabular}{lccc}
\hline & $\begin{array}{c}\text { Com moradia } \\
\mathrm{N}^{\circ} .(\%)\end{array}$ & $\begin{array}{c}\text { Consumo de } \\
\text { bebida alcoólica } \\
\mathrm{N}^{\circ} .(\%)\end{array}$ & $\begin{array}{c}\text { Uso de drogas } \\
\text { injetáveis } \\
\mathrm{N}^{\circ} .(\%)\end{array}$ \\
\hline Sim & $266(88,4)$ & $107(35,5)$ & $122(40,5)$ \\
Não & $35(11,6)$ & $61(20,3)$ & $167(55,5)$ \\
Sem informação & $0(0,0)$ & $133(44,2)$ & $12(4,0)$ \\
\hline Total & $301(100,0)$ & $301(100,0)$ & $301(100,0)$ \\
\hline
\end{tabular}

4.1.8 - Distribuição do número de internações prévias ao tratamento de TB

Do total de casos analisados, $70(23,3 \%)$ pacientes foram internados pelo menos uma vez antes do início do tratamento de TB e após o diagnóstico de HIV+; 201 (66,8\%) pacientes não tiveram internação prévia mas sim 
posterior e no prontuário de $30(10,0 \%)$ pacientes não havia referência quanto à internações.

A Tabela 5 mostra o número de internações prévias ao início do tratamento de TB segundo hospital. O número total de internações é maior que o número de casos com internação prévia pois alguns pacientes internaram mais de uma vez antes do início de tratamento de TB. O hospital que apresentou maior número de internações foi o Hospital Guilherme Álvaro (52 internações) seguido da Santa Casa de Santos onde foram registradas 13 internações prévias ao tratamento de TB.

TABELA 5. Distribuição do número de internações prévias ao início de tratamento de TB dos casos de TB/HIV segundo hospital, Baixada Santista1993-2003

\begin{tabular}{lcc}
\hline Hospital & Número de internações & $\%$ \\
\hline Hospital Guilherme Álvaro & 52 & 57,8 \\
Santa Casa de Santos & 13 & 14,4 \\
Hospital Estivadores & 7 & 7,7 \\
Hospital São José & 2 & 2,2 \\
Hospital Santo Amaro & 3 & 3,4 \\
Outros Hospitais da região & 6 & 6,7 \\
Outro hospital fora da região & 7 & 7,8 \\
\hline Total & 90 & 100,0 \\
\hline
\end{tabular}


O motivo da internação prévia foi referido nos prontuários de $72,8 \%$ dos pacientes que internaram. Em $18(25,7 \%)$ casos a tuberculose estava relacionada como motivo de internação; $33(47,1 \%)$ casos foram internados por outros motivos relacionados ao HIV e em 19 (27,2\%) casos não havia informação quanto ao motivo de internação.

4.1.9- Distribuição dos casos segundo ano de diagnóstico de tuberculose

A Figura 1 mostra a distribuição dos casos segundo ano de diagnóstico de tuberculose. O maior número de casos foi detectado entre os anos de 1996 e 2001 sendo 1997 o ano com maior número de casos detectados. Os dados referentes ao ano de 2003 são provisórios, coletados até o mês de março.

Figura 1- D istribuição dos casos de TB/H IV segundo anode diagnóstico de tuberculose, Baixada Santista - 1993-2003*

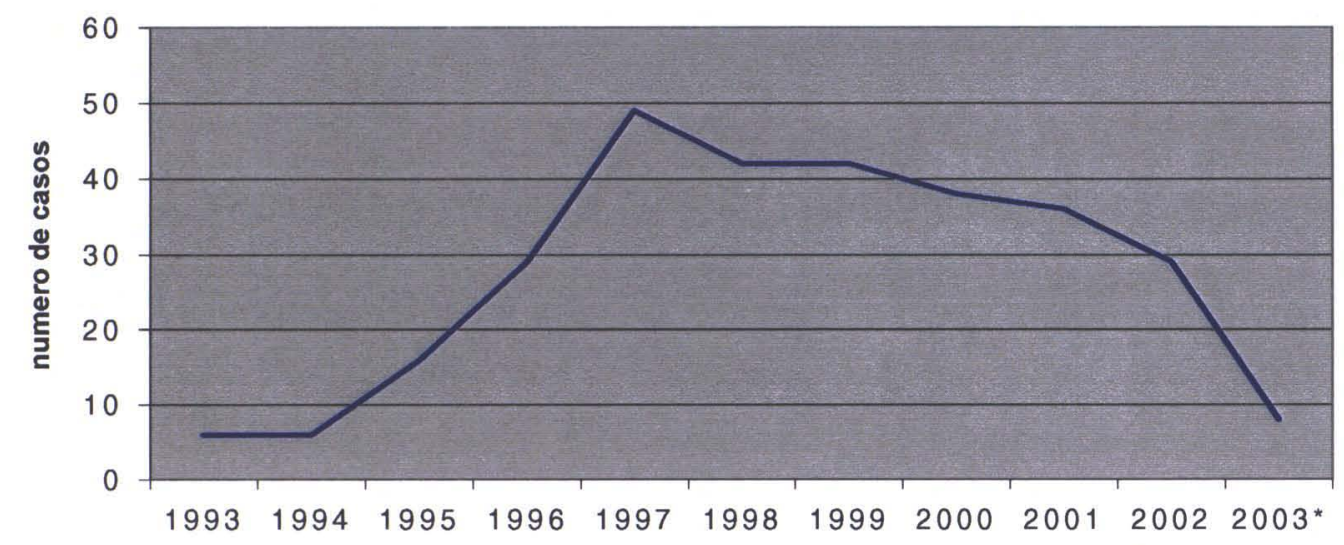

*dados provisórios até março de 2003 
4.1.10- Distribuição dos casos segundo antecedentes de tratamento com drogas anti-tuberculose

O tratamento prévio para tuberculose foi referido ou constou em prescrições de $127(42,2 \%)$ pacientes, foi negado por 129 (42,9\%). Em 45 $(15,0 \%)$ não havia informação a respeito desta variável.

\section{2- Perfil de resistência}

4.2.1- Distribuição dos casos segundo sensibilidade às drogas antituberculose

Das cepas de M.tuberculosis isoladas dos 301 pacientes, 244 (81,1\%) foram sensíveis a todas as drogas testadas e $57(18,9 \%)$ casos foram resistentes a pelo menos uma droga sendo $32(10,6 \%)$ resistentes a no mínimo isoniazida e rifampicina.

Dos 57 casos resistentes $32(56,1 \%)$ apresentaram TB multirresistente; $21(36,8 \%)$ monorresistência e $4(7,1 \%)$ casos apresentaram resistência a duas ou mais drogas.

Monorresistência à I correspondeu a 3,6\% do total de casos, à $R$ $2,0 \%$, à $\mathrm{P} 0,3 \%$ e à $\mathrm{S} \quad 1,0 \%$. Não foi verificada resistência a etambutol. (Tabela 6) . 
TABELA 6. Distribuição dos casos de TB/HIV segundo perfil de sensibilidade do M. tuberculosis às drogas, Baixada Santista 1993-2003

\begin{tabular}{lcc}
\hline Padrão de sensibilidade & $\mathrm{N}^{\circ}$. & $\%$ \\
\hline Sensíveis & 244 & 81,1 \\
Resistentes & & \\
& & \\
$\mathrm{R}$ & 6 & 2,0 \\
$\mathrm{I}$ & 11 & 3,6 \\
$\mathrm{P}$ & 1 & 0,3 \\
$\mathrm{E}$ & 0 & 0,0 \\
$\mathrm{~S}$ & 3 & 1,0 \\
$\mathrm{R}+\mathrm{I}$ & 14 & 4,7 \\
$\mathrm{R}+\mathrm{S}$ & 2 & 0,7 \\
$\mathrm{R}+\mathrm{I}+\mathrm{P}$ & 12 & 4,0 \\
$\mathrm{R}+\mathrm{I}+\mathrm{E}$ & 3 & 1,0 \\
$\mathrm{R}+\mathrm{I}+\mathrm{S}$ & 1 & 0,3 \\
$\mathrm{R}+\mathrm{I}+\mathrm{P}+\mathrm{S}$ & 2 & 0,7 \\
$\mathrm{I}+\mathrm{P}$ & 1 & 0,3 \\
$\mathrm{I}+\mathrm{P}+\mathrm{E}$ & 1 & 0,3 \\
Subtotal & 57 & 18,9 \\
& & \\
\hline TOTAL & 301 & 100,0 \\
\hline
\end{tabular}

4.2.2- Distribuição dos casos de TB sensível e resistente segundo tratamento anterior com drogas antituberculose

Os casos de TB sensível apresentaram em média 0,7 tratamentos anteriores. Entre os casos que apresentam algum tipo de resistência o número médio de tratamentos anteriores foi de 1,7 . Os casos com resistência a uma ou 
mais drogas apresentaram em média 1,3 tratamentos anteriores e os casos de multirresistência 2,0 tratamentos anteriores em média.

Do total de casos de TB sensível $118(48,4 \%)$ pacientes não receberam tratamento prévio com tuberculostáticos, o tratamento anterior estava referido no prontuário de $87(35,7 \%)$ pacientes e esta informação não constava no prontuário de 39 (16\%) pacientes com TB sensível. Entre os casos com algum tipo de resistência $40(70,2 \%)$ apresentaram registro de tratamento anterior, 11 (19,3\%) negaram uso de tuberculostáticos e em 6 (10,5\%) casos esta informação não constava no prontuário.

Entre os casos de tuberculose multirresistente $23(71,9 \%)$ pacientes haviam sido tratados previamente, $5(15,6 \%)$ não haviam sido tratados e em 4 $(12,5 \%)$ casos não havia registro desta informação. (Tabela 7)

Entre os pacientes com resistência a uma ou mais drogas $17(68,0 \%)$ pacientes foram tratados anteriormente, $6(24,0 \%)$ não foram tratados e $2(8,0)$ casos esta informação não constava no prontuário. (Tabela 7) 
TABELA 7. Distribuição dos casos de TB resistentes e sensíveis em indivíduos HIV positivos segundo tratamento prévio com drogas antituberculose, Baixada Santista- 1993-2003

\begin{tabular}{lcccc}
\hline $\begin{array}{l}\text { Tratamento } \\
\text { anterior }\end{array}$ & $\begin{array}{c}\text { Casos } \\
\text { sensíveis (\%) }\end{array}$ & $\begin{array}{c}\text { Casos resistentes } \\
(\%)\end{array}$ & $\begin{array}{c}\text { Casos } \\
\text { multirresistentes } \\
(\%)\end{array}$ & Total (\%) \\
\hline Sim & $87(35,7)$ & $17(68,0)$ & $23(71,9)$ & $127(42,2)$ \\
Não & $118(48,3)$ & $6(24,0)$ & $5(15,6)$ & $129(42,9)$ \\
$\begin{array}{l}\text { Sem } \\
\text { informação }\end{array}$ & $39(16,0)$ & $2(8,0)$ & $4(12,5)$ & $45(14,9)$ \\
\hline Total & $244(100,0)$ & $25(100,0)$ & $32(100,0)$ & $301(100,0)$ \\
\hline
\end{tabular}

A Tabela 8 mostra a distribuição dos casos de tuberculose resistente segundo droga e resistência adquirida e primária. Considerando-se o total desses casos, a resistência adquirida foi observada em 40 (70,2\%) pacientes e resistência primária em $11(19,3 \%)$.

Entre os casos com resistência à S 66,7\% apresentaram resistência primária, à $\mathrm{I}, 27,3 \%$ e à $\mathrm{R}, 16,7 \%$. Não foi verificada resistência primária a pirazinamida. Os casos resistentes à associação $\mathrm{R}+\mathrm{I}+\mathrm{P}$ apresentaram a maior proporção de resistência primária $(33,3 \%)$ entre os casos multirresistentes, seguida da associação $R+I(7,1 \%)$. 
Com exceçãCS da $\mathrm{S}$ todas as drogas apresentam maiores taxas de resistência adquiridzeem relação à resistência primária. Entre os casos com resistência a associaç-Fo $\mathrm{R}+\mathrm{P}, 78,6 \%$ apresentaram resistência adquirida.

Para o total cos amostra os percentuais de monorresistência primária foram de $0,9 \%$ pami Isoniazida, $0,6 \%$ para Estreptomicina e $0,3 \%$ para Rifampicina. Não foicrerificada resistência primária à Pirazinamida.

TABELA 8. Distrib dção dos casos de tuberculose resistente em indivíduos HIV positivos segupado padrão de resistência às drogas anti-tuberculose, Baixada Santista - 1003-2003

\begin{tabular}{|c|c|c|c|c|}
\hline $\begin{array}{l}\text { Perfil de } \\
\text { resistência }\end{array}$ & $\begin{array}{l}\text { Resistência } \\
\text { Pa nária } \\
\text { P (\%) }\end{array}$ & $\begin{array}{c}\text { Resistência } \\
\text { Adquirida } \\
\mathrm{N}^{\mathrm{o}}(\%)\end{array}$ & $\begin{array}{c}\text { Resistência } \\
\text { indeterminada } \\
\mathrm{N}^{\circ}(\%)\end{array}$ & $\begin{array}{c}\text { Total } \\
\mathrm{N}^{\circ}(\%)\end{array}$ \\
\hline$\overline{\mathrm{R}}$ & 1) $(6,7)$ & $5(83,3)$ & 0 & $6(100,0)$ \\
\hline I & 3) 27,3$)$ & $8(72,7)$ & 0 & $11(100,0)$ \\
\hline$P$ & 0 & $1(100,0)$ & 0 & $1(100,0)$ \\
\hline $\mathrm{E}$ & 0 & 0 & 0 & $0(0,00)$ \\
\hline $\mathrm{S}$ & 2) 56,7$)$ & 0 & $1(33,3)$ & $3(100,0)$ \\
\hline $\mathrm{R}+\mathrm{I}$ & $17,1)$ & $11(78,6)$ & $2(14,3)$ & $14(100,0)$ \\
\hline $\mathrm{R}+\mathrm{S}$ & 0 & $2(100,0)$ & 0 & $2(100,0)$ \\
\hline $\mathrm{R}+\mathrm{I}+\mathrm{P}$ & 4) 33,3$)$ & $7(58,3)$ & $1(8,4)$ & $12(100,0)$ \\
\hline $\mathrm{R}+\mathrm{I}+\mathrm{E}$ & 0 & $2(66,7)$ & $1(33,3)$ & $3(100,0)$ \\
\hline $\mathrm{R}+\mathrm{I}+\mathrm{S}$ & 0 & $1(100,0)$ & 0 & $1(100,0)$ \\
\hline $\mathrm{R}+\mathrm{I}+\mathrm{P}+\mathrm{S}$ & 0 & $2(100,0)$ & 0 & $2(100,0)$ \\
\hline $\mathrm{I}+\mathrm{P}$ & 0 & 0 & $1(100,0)$ & $1(100,0)$ \\
\hline $\mathrm{I}+\mathrm{P}+\mathrm{E}$ & 0 & $1(100,0)$ & 0 & $1(100,0)$ \\
\hline TOTAL & 11) 19,3$)$ & $40(70,2)$ & $6(10,5)$ & $57(100,0)$ \\
\hline
\end{tabular}


4.2.3- Distribuição dos casos sensíveis e resistentes segundo unidade de atendimento

A distribuição dos casos sensíveis e resistentes segundo município de atendimento está representada na Tabela 9. O município com maior porcentagem de casos resistentes foi Praia Grande com 37,5\% de casos resistentes, seguido de São Vicente com 26,3\% e Guarujá com $20 \%$.

TABELA 9. Distribuição dos casos de TB sensíveis e casos de TB resistentes em indivíduos HIV positivos segundo município de atendimento, Baixada Santista- 1993-2003

\begin{tabular}{lccc}
\hline Município de atendimento & $\begin{array}{c}\text { Casos sensíveis } \\
\mathrm{N}^{\circ}(\%)\end{array}$ & $\begin{array}{c}\text { Casos } \\
\text { resistentes } \\
\mathrm{N}^{\circ}(\%)\end{array}$ & $\begin{array}{c}\text { Total } \\
\mathrm{N}^{\circ}(\%)\end{array}$ \\
\hline CRAIDS- Santos & $200(82,3)$ & $43(17,7)$ & $243(100,0)$ \\
SAE- São Vicente & $14(73,7)$ & $5(26,3)$ & $19(100,0)$ \\
NVS- Cubatão & $13(81,3)$ & $3(18,8)$ & $16(100,0)$ \\
HDWR- Guarujá & $12(80,0)$ & $3(20,0)$ & $15(100,0)$ \\
SAE- Praia Grande & $5(62,5)$ & $3(37,5)$ & $8(100,0)$ \\
\hline Total & $244(81,1)$ & $57(18,9)$ & $301(100,0)$ \\
\hline
\end{tabular}


4.2.4- Distribuição dos casos de $\mathrm{TB}$ sensível e resistente segundo ano de diagnóstico

A distribuição dos casos segundo ano de diagnóstico é mostrada na Tabela 10. O teste do $\chi^{2}$ para esta distribuição foi de 11,3 com 20 graus de liberdade. Não há diferenças estatisticamente significativa entre as proporções de casos de TB multirresistente e TB resistente em relação ao ano calendário.

TABELA 10 - Distribuição dos casos de TB sensíveis e resistentes em indivíduos HIV positivos segundo ano de diagnóstico de tuberculose, Baixada Santista $-1993-2003$

\begin{tabular}{lcccc}
\hline $\begin{array}{l}\text { Ano de } \\
\text { diagnóstico }\end{array}$ & $\begin{array}{c}\text { TB sensível } \\
\mathrm{N}^{\circ}(\%)\end{array}$ & $\begin{array}{c}\text { TB } \\
\text { multirresistente } \\
\mathrm{N}^{\circ}(\%)\end{array}$ & $\begin{array}{c}\text { TB resistente } \\
\mathrm{N}^{\circ}(\%)\end{array}$ & $\begin{array}{c}\text { Total } \\
\mathrm{N}^{\circ}(\%)\end{array}$ \\
\hline 1993 & $6(100,0)$ & $0(0,00)$ & $0(0,00)$ & $6(100,0)$ \\
1994 & $5(83,4)$ & $0(0,00)$ & $1(16,6)$ & $6(100,0)$ \\
1995 & $15(93,7)$ & $1(6,3)$ & $0(0,00)$ & $16(100,0)$ \\
1996 & $24(82,7)$ & $2(6,9)$ & $3(10,4)$ & $29(100,0)$ \\
1997 & $38(77,5)$ & $5(10,2)$ & $6(12,3)$ & $49(100,0)$ \\
1998 & $36(85,7)$ & $4(9,5)$ & $2(4,8)$ & $42(100,0)$ \\
1999 & $32(76,0)$ & $5(12,0)$ & $5(12,0)$ & $42(100,0)$ \\
2000 & $30(78,9)$ & $5(13,1)$ & $3(8,0)$ & $38(100,0)$ \\
2001 & $28(77,8)$ & $5(13,8)$ & $3(8,4)$ & $36(100,0)$ \\
2002 & $25(86,2)$ & $3(10,4)$ & $1(3,4)$ & $29(100,0)$ \\
2003 & $5(62,5)$ & $2(25,0)$ & $1(12,5)$ & $8(100,0)$ \\
\hline Total & $244(81,1)$ & $32(10,6)$ & $25(8,3)$ & $301(100,0)$ \\
\hline$\chi^{2}=11,30 p=0,938$ & & & &
\end{tabular}




\section{3- Variáveis associadas}

A análise estatística de variáveis associadas à TB resistente em pacientes HIV positivos é mostrada na Tabela 11. Não houve associação estatisticamente significante entre as variáveis: sexo, situação de moradia, consumo de bebidas alcoólicas, uso de drogas injetávies e uso de medicamentos antiretrovirais ou HAART e tuberculose resistente. A variável tratamento anterior com drogas anti-tuberculose mostrou a maior associação $(\mathrm{OR}=4,93 ;$ IC $95 \%=>2,27-10,94)$, seguido pela tempo de evolução do HIV e hospitalização prévia ao diagnóstico de TB. 
TABELA 11. Análise univariada para avaliação da associação entre TB resistente e as variáveis de estudo

\begin{tabular}{|c|c|c|c|c|}
\hline Variável & $\begin{array}{c}\text { Sensível } \\
\mathbf{n}^{\circ}\end{array}$ & $\begin{array}{c}\text { Resistente } \\
\mathbf{n}^{\mathbf{0}}\end{array}$ & Valor de $p$ & OR $(95 \%$ IC) \\
\hline \multicolumn{5}{|l|}{ Sexo } \\
\hline Masculino & 168 & 40 & 0,8457 & 1,00 \\
\hline Feminino & 76 & 17 & & $0,94(0,47-1,85)$ \\
\hline \multicolumn{5}{|l|}{ Faixa Etária } \\
\hline $20-30$ & 62 & 20 & & 1,00 \\
\hline $31-34$ & 59 & 12 & 0,258 & $0,63(0.28-1.40)$ \\
\hline $35-49$ & 52 & 14 & 0,648 & $0,83(0,38-1,81)$ \\
\hline $50-70$ & 71 & 11 & 0,076 & $0,48(0,21-1,08)$ \\
\hline \multicolumn{5}{|l|}{ Domicílio } \\
\hline Não & 30 & 5 & 0,4550 & 1,00 \\
\hline Sim & 214 & 52 & & $1,46(0,50-4,55)$ \\
\hline \multicolumn{5}{|c|}{ Consumo de Alcool } \\
\hline Não & 50 & 11 & 0,4997 & 1,00 \\
\hline Sim & 83 & 24 & & $1,31(0,55-3,17)$ \\
\hline \multicolumn{5}{|c|}{ Uso de droga injetável } \\
\hline Não & 138 & 29 & 0,3113 & 1,00 \\
\hline Sim & 95 & 27 & & $1,35(0,72-2,54)$ \\
\hline \multicolumn{5}{|r|}{ (1) } \\
\hline Não & 195 & 42 & 0,2640 & 1,00 \\
\hline $\operatorname{Sim}$ & 44 & 14 & & $1,48(0,70-3,11)$ \\
\hline \multicolumn{5}{|l|}{ HAART } \\
\hline Não & 178 & 40 & 0,6401 & 1,00 \\
\hline Sim & 61 & 16 & & $1,17(0,58-2,35)$ \\
\hline \multicolumn{5}{|c|}{ Hospitalização prévia } \\
\hline Não & 168 & 33 & 0,0497 & 1,00 \\
\hline Sim & 51 & 19 & & $1,90(0,94-3,82)$ \\
\hline \multicolumn{5}{|c|}{ Tempo de evolução do } \\
\hline HIV & & & 0,01258 & \\
\hline Até 4 anos & 176 & 31 & & 1,00 \\
\hline 5 ou mais & 67 & 25 & & $2,12(1,11-4,04)$ \\
\hline \multicolumn{5}{|l|}{ Linfócitos CD4+ } \\
\hline $500 / \mathrm{mm} 3$ ou mais & 21 & 22 & & 1,00 \\
\hline $200-499 / \mathrm{mm} 3$ & 55 & 19 & 0,510 & $1,45(0,81-3,27)$ \\
\hline $0-199 / \mathrm{mm} 3$ & 104 & 22 & 0,830 & $0,88(0,30-2,61)$ \\
\hline \multicolumn{5}{|c|}{ Tratamento anterior } \\
\hline Não & 118 & 11 & 0.0000 & 1,00 \\
\hline $\operatorname{Sim}$ & 87 & 40 & & $4,93(2,27-10,94)$ \\
\hline
\end{tabular}


As variávies que foram significativamente associadas a TB resistente na análise univariada foram incluídas em modelos de análise multivariada.

Ajustando-se todas as variáveis testadas por faixa etária, o desenvolvimento de tuberculose resistente mostrou-se independentemente e de forma significativa associada a história de tratamento anterior com drogas antituberculose $(\mathrm{OR}=5,49$ : IC95\% 2,60-11,60). As variáveis: tempo de evolução do HIV e hospitalização prévia não mostraram asssociação significativa mesmo quando ajustadas por faixa etária e foram excluídas do modelo final. (Tabela 12)

TABELA 12 - Análise multivariada segundo variáveis explicativas da resistência às drogas anti-tuberculose, ajustada por faixa etária.

\begin{tabular}{lcc}
\hline Variável & OR & IC 95\% \\
\hline Tratamento anterior & & \\
Não & 1,00 & \\
Sim & 5,49 & $2,60-11,60$ \\
Faixa etária & & \\
$20-30$ & 1,00 & \\
$31-34$ & 0,46 & $0,18-1,15$ \\
$35-49$ & 0,50 & $0,20-1,22$ \\
$50-70$ & 0,29 & $0,11-0,75$ \\
\hline
\end{tabular}




\section{4 - Análise de causa de óbito}

Do total de casos analisados, $111(36,8 \%)$ faleceram no período de seguimento do estudo e $65(21,6 \%)$ pacientes não apresentaram registro de comparecimento na unidade de saúde até 6 meses antes do término da pesquisa e foram considerados como abandono de tratamento.

Dos 111 óbitos ocorridos entre pacientes HIV positivos com tuberculose, foram recuperados dados sobre 99 falecidos por meio das respectivas declarações de óbito ou correspondentes registros nos bancos do Sistema Nacional de Informações sobre Mortalidade ou da Fundação Sistema Estadual de Análise de Dados (SEADE) do Estado de São Paulo. Verificou-se que a tuberculose como causa associada de morte foi mencionada em 49 $(49,5 \%)$ desses registros, em $50(50,5 \%)$ óbitos outras causas foram associadas a AIDS (Tabela 13).

TABELA 13. Distribuição dos 99 óbitos de 301 pacientes TB/HIV segundo causa associada de morte, Baixada Santista 1993-2003

\begin{tabular}{llc}
\hline Causas associadas a AIDS & $\mathrm{N}^{\mathbf{0}}$ & $\%$ \\
\hline Tuberculose & 49 & 49,5 \\
Outras causas & 50 & 50,5 \\
\hline Total & 99 & 100,0 \\
\hline
\end{tabular}




\section{5- Discussão}

O presente estudo mostrou uma prevalência de $18,9 \%$ de resistência às drogas antituberculose nos pacientes HIV positivos estudados. A variável associada à TB resistente foi tratamento anterior com tuberculostáticos $(\mathrm{OR}=5,49 ; \mathrm{IC} 95 \% 2,60-11,60)$.

Estes dados não diferem muito dos relatados na literatura. PINTO 1998, ao realizar estudo semelhante com 431 pacientes com AIDS atendidos em Centro de Referência e Treinamento DST/AIDS em São Paulo (CRTAIDS), encontrou resistência em 19\% dos casos. FANDINHO et al, 1999 encontraram prevalência de $16,6 \%$ de resistência entre casos atendidos em hospital de referência para AIDS no Rio de Janeiro. Nos Estados Unidos, BLOCH et al. 1994 encontraram prevalência de 14,2\% de resistência a uma ou mais drogas entre pacientes HIV positivos.

Para uma melhor avaliação da representatividade da amostra, os resultados obtidos foram comparados com os casos TB/HIV notificados nos municípios estudados a partir de 1997, ano em que os registros de notificação foram informatizados.

No presente estudo houve predomínio do sexo masculino $(69,1 \%)$ e média de idade de 35,5 anos. Estes dados assemelharam-se muito aos casos de 
TB/AIDS notificados na região, dos quais $71 \%$ são do sexo masculino com média de idade de 34,9 anos.

Em nosso estudo foram analisados somente os casos com comprometimento pulmonar. A forma clínica pulmonar isolada foi diagnosticada em $90,7 \%$ dos casos e o diagnóstico da forma pulmonar e extrapulmonar ocorreu em 9,3\%. Estes dados foram muito próximos dos encontrados entre os casos de TB/HIV notificados, dos quais $91,9 \%$ apresentaram somente a forma pulmonar e $8,9 \%$ foram diagnosticados como TB pulmonar e extrapulmonar.

Do total de casos analisados neste estudo, $42,2 \%$ apresentaram em seus prontuários registro de tratamento anterior com tuberculostáticos. Entre os casos notificados nos cinco municípios, $30,59 \%$ foram tratados anteriormante com drogas antituberculose. Esta diferença sugere que possa ter ocorrido vício de seleção da amostra analisada visto que a maioria dos casos tratados anteriormente apresentam maior chance de desenvolvimento de TB resistente.

A porcentagem de casos com tratamento anterior aqui apresentados também diferiram da relatada por PINTO 1998. Naquele estudo, 20,9\% dos casos referiram tratamento anterior. 


\section{1- Perfil de Resistência}

O perfil de resistência às drogas, aqui apresentado, se assemelhou ao relatado em inquérito mundial realizado pela OMS (ESPINAL et al. 2001): a taxa de resistência adquirida foi maior que a de resistência primária; a multirresistência foi mais freqüente como resistência adquirida que como resistência primária; os percentuais de monoressistência primária à Isoniazida e à Estreptomicina foram próximos entre si e maiores que os verificados para a Rifampicina; não foi detectado neste grupo um padrão de resistência raro como o da resistência primária ao Etambutol.

Segundo TOMAN 1980, a taxa de resistência primária esperada para países em desenvolvimento é de $15 \%$; a encontrada no presente estudo foi de 19,3\%. Esta freqüência foi também maior que a encontrada em outros inquéritos realizados no Brasil. BARRETO e MARTINS 1988, no período de 1986 a 1988, registrou resistência primária de 15,2\% e SILVA et al. 1992 encontrou taxa de $16,9 \%$.

Em comparação ao estudo de SILVA et al. 1992, nossa casuística apresentou taxas menores de monorresistência primária a Isoniazida e Estreptomicina. No presente estudo a taxa de monorresistência primária a Isoniazida foi de $0,9 \%$ enquanto SILVA et al. 1992 encontraram taxa de 
$2,7 \%$. A monorresistência primária a estreptomicina aqui encontrada foi de $0,6 \%$, no citado estudo a taxa para estreptomicina foi de $4,4 \%$.

A distribuição das taxas de monorresistência primária aqui apresentadas foram mais semelhantes às descritas por PINTO 1998 que encontrou taxas de monorresistência primária à Isoniazida de $1,2 \%$ e à Estreptomicina de $0,9 \%$.

Ao contrário do que foi demonstrado em vários estudos (SILVA et al. 1992; COHN et al. 1997; ESPINAL et al. 2001) nesta casuística a freqüência de monorresistência à Rifampicina foi maior que a verificada para a Estreptomicina.

Em nosso estudo, embora a monoresistência primária a rifampicina $(0,3 \%)$ tenha sido menor que a observada para estreptomicina $(0,6 \%)$, a resistência total (primária e adquirida) à esta droga $(2,0 \%)$ foi maior que a resistência total à estreptomicina $(1,0 \%)$. Estudos realizados em indivíduos HIV positivos no município de Bauru - SP (BAPTISTA et al. 2002) e em dois hospitais do Rio de Janeiro (FANDINHO et al. 1999) não encontraram monorresistência à Rifampicina.

A monorresistência a Rifampicina foi relatada por PINTO 1998. Naquele estudo houve freqüência relativamente alta de monorresistência (predominantemente adquirida), que resultou também maior que a verificada para a estreptomicina. 
A monorresistência adquirida à Rifampicina vem sendo referida como um aspecto peculiar dos casos de TB/AIDS (LUFTEY et al. 1996; SANDMAN et al 1999), várias hipóteses foram aventadas para explicar este fenômeno sem que haja, entretanto, demonstração definitiva que favoreça algum aspecto em particular. MUNSIFF et al. 1997 relatam a não adesão ao tratamento como a explicação mais plausível para estes casos.

O percentual de multirresistência verificado em nosso trabalho $(10,6 \%)$ foi semelhante ao encontrado por PINTO 1998 (11,3\%). No entanto, este percentual foi menor do que o citado em outros estudos em indivíduos HIV+ no Brasil. No Rio de Janeiro, FANDINHO et al 1995 registraram, em 34 pacientes HIV positivos, $15 \%$ de resistência à associação $\mathrm{R} / \mathrm{I}$. No mesmo Estado, em 48 pacientes HIV positivos, MACHADO et al. 1994 encontraram taxa de multirresistência de 12,5\%.

A comparação da distribuição dos padrões de multirresistência observados entre nossos casos com os referidos em pacientes HIV negativos, particularmente em São Paulo (MELO et al 1996, SILVA et al 1992), demonstra ter havido uma proporção maior de multirresistência entre os pacientes deste trabalho. Em estudo recente que analisou a resistência entre pacientes HIV negativos e positivos, BAPTISTA et al. 2002 encontraram taxa de multirresistência de 5,5\%. 
Em estudos realizados em outros Estados brasileiros a multirresistência resultou maior que a apresentada neste trabalho. No Estado do Ceará a taxa de multirresistência entre pacientes HIV negativos foi de 17,7\% (BARROSO et al. 2001). Em estudo que analisou 170 amostras de M. tuberculosis isoladas de pacientes HIV negativos e positivos, no Estado do Rio Grande do Sul, a taxa de multirresistência foi de 21,7\% ( ALMEIDA DA SILVA et al. 2001).

Considerando o total da amostra analisada, a taxa de multirresistência primária foi de $1,66 \%$. Esta freqüência se mostrou mais próxima da apresentada, entre pacientes HIV negativos, por MELO et al. $1996(1,5 \%)$ e por PABLOS-MENDEZ et al. 1998 , em inquérito nacional $(2,1 \%)$, do que a apresentada, entre pacientes HIV positivos, por PINTO $1998(3,2 \%)$.

A freqüência de multirresistência adquirida apresentada em nosso trabalho $(8,3 \%)$ foi semelhante a observada em inquérito mundial $(9,3 \%)$ (ESPINAL et al. 2001), e maior que a registrada em estudo nacional com pacientes HIV positivos (6,2\%) (PINTO 1998).

A taxa de resistência adquirida aqui apresentada (70,2\%) foi maior que a registrada em outros estudos. BAPTISTA et al. 2002 encontraram taxa de 33,4\%; PINTO 1998, taxa de 45\% e no estudo de FANDINHO et al. 1999, $13,3 \%$ dos pacientes HIV positivos foram tratados anteriormente com tuberculostáticos. 
Em média, os indivíduos com resistência a pelo menos uma droga apresentaram 1,7 tratamentos anteriores de TB enquanto os multirresistentes tiveram 2 tratamentos anteriores em média.

Entre os 40 indivíduos com diagnóstico de TB resistente adquirida incluídos em nosso estudo foi possível detectar o periodo de tratamento em 33 casos (17 pacientes com TB multirresistente e 16 com TB resistente). Analisando o primeiro tratamento destes pacientes foi possível verificar que 22 pacientes abandonaram o tratamento, 10 foram considerado tratados e 1 faleceu. Em 10 casos o tempo de tratamento foi maior que 9 meses sendo que 4 abandonaram, 1 foi a óbito e 5 foram considerados curados.

Vários estudos têm demonstrado a co-infecção com o HIV como fator de risco associado a resistência adquirida (PATEL et al. 1995; MARCH et al. 1997; BRADFORD et al. 1996). Algumas hipóteses como falhas no tratamento, reinfecção exógena (SMALL et al. 1993), interação medicamentosa com drogas para tratamento de AIDS (LEE e SAFRIN 1992) e má-absorção às drogas antituberculose têm sido associados a resistência de M. tuberculosis durante ou logo após o tratamento em pacientes HIV positivos (BERNING et al. 1992; PELOQUIM et al. 1993). 


\section{2- Associação entre variáveis estudadas e resistência às drogas}

Em nosso estudo não foi possível detectar associação entre resistência e fatores considerados predisponentes ao abandono do tratamento tais como uso de drogas injetáveis, alcoolismo e falta de moradia.

De acordo com estudo realizado em Amsterdã, o uso de drogas injetáveis parece estar associado não apenas a infecção pelo HIV mas também a tuberculose; o risco de adquirir a tuberculose em indivíduos HIV positivos usuários de droga foi maior do que entre indivíduos que faziam uso de drogas mas eram HIV negativos (KEIZER et al. 2000).

Nos EUA, para fins de planejamento de ações preventivas visando o controle da TB, os dependentes de drogas são considerados como grupo de alto risco para esta doença (CDC 1990). Na avaliação de PERLMAN et al. 1995 a dependência seria mais comumente um dado indicativo de um modo de vida em que prevalecem outros fatores de risco para $\mathrm{TB}$ do que propriamente um fator de risco independente para manifestação da doença.

Em um estudo de coorte realizado na Espanha que visou avaliar os fatores de risco para abandono de tratamento de tuberculose entre pacientes HIV positivos o único fator associado foi o uso de drogas injetáveis (ORTEGA et al. 1997).

No presente estudo, assim como referido por SALOMON et al. 1994, o uso de drogas injetáveis não se mostrou associado a TB resistente. 
Ao contrário de alguns trabalhos o consumo de bebidas alcoólicas não se mostrou estatisticamente associado a resistência. Na Espanha, o alcoolismo foi referido como fator de risco para tuberculose resistente em estudo realizado com pacientes HIV positivos e negativos (TORRES et al. 2000). No Brasil, em um recente estudo que avaliou os aspectos epidemiológicos da TBMR em um serviço de referência de São Paulo, o alcoolismo foi citado como condição associada à multirresistência (MELO et al. 2003).

Em nosso estudo a porcentagem de casos resistentes que relataram uso de bebidas alcoólicas foi menor (22,45\%) do que a verificada por PINTO 1998 $(35,59)$.

A população carcerária tem sido considerada de alto risco de TBMR devido às super lotações, poucos cuidados com a saúde, alta prevalência de grupos de risco e diagnóstico tardio e incompleto de tuberculose (LOURENÇO et al. 2000). Em um estudo realizado em 58 amostras de $M$ tuberculoses de pacientes do Sanatório Penal Masculino do Rio de Janeiro, foi obervada resistência a pelo menos um a droga em $17,2 \%$ dos casos e a multiresistência foi diagnosticada em 3,4\% dos detentos (LOURENÇO et al. 2000). No entanto, em nossa casuística, devido ao grande número de prontuários sem esta informação $(76,7 \%)$ não foi possível fazer uma análise apropriada e optou-se pela exclusão da variável. 
Em estudo caso-controle nos EUA, a hospitalização, até seis meses antes, mostrou-se estatisticamente associada a TBMR (EDLIN,1992).

Em nossso estudo, a análise univariada entre hospitalização e tuberculose resistente mostrou um odds ratio de 1,90 com intervalo de $95 \%$ de confiança entre 0,94 e 3,82 (contendo o valor 1,0 ) e um valor de $p<0.05$. Se considerarmos que o intervalo de confiança contém o número 1,0 , deveríamos concluir que esta associação não é estatisticamente significativa; se considerarmos o valor de $\mathrm{p}$, menor que $5 \%$, esta associação deveria ser considerada existente do ponto de vista estatístico. Esta contradição decorre das diferentes formas de cálculo matemático do intervalo de confiança e do $\mathrm{p}$. Não encontramos na literatura referência ao resultado que deve ser priorizado.

Esta associação entre hospitalização prévia e tuberculose resistente não foi confirmada em análise multivariada e não consta do modelo final. No entanto, o conhecimento epidemiológico deve se sobrepor ao rigor estatístico neste caso pois, no período de estudo, as enfermarias de tuberculose e de pacientes com HIV/AIDS, do hospital regional de referência (onde 57,8\% da população estudada foi internada) conviviam em mesma ala sem barreiras. Mais importante que definir se existe ou não associação neste caso, é manter a atenção para a questão da transmissão intrainstitucional suspeita. Portanto fazse necessário um estudo pormenorizado destas questões visto que a qualidade da informação dos prontuários aqui analisados e inexistência de informação a 
respeito do tempo de hospitalização, duração e tipo de isolamento e outros parâmetros especificamente vinculados à estrutura hospitalar que comprometaram a análise desta variável.

Utilizando as informações coletadas nos prontuários foi possível verificar o motivo de internação em $72,8 \%$ dos casos sendo que em 18 $(25,7 \%)$ a tuberculose estava relacionada como causa de internação. Em um estudo realizado em Cambojia 26\% dos casos de HIV estudados apresentaram tuberculose como motivo de internação (SENYA et al. 2003).

$\mathrm{Na}$ literatura médica, a contagem de células $\mathrm{CD} 4+$ em pacientes $\mathrm{HIV}$ positivos tem sido demonstrada como bom marcador para progressão da doença visto que existe uma correlação inversa entre contagem de CD4 e desenvolvimento de infecções oportunistas e óbito (BARNES e BARROWS, 1993; NUNN el al. 1994; ACKAH et al. 1995). Estudos em países desenvolvidos têm demonstrado que embora a tuberculose seja diagnosticada em pacientes HIV positivos com diferentes contagens de CD4+, a incidência de TB é maior naqueles com contagem de linfócitos abaixo de $200 / \mathrm{mm}^{3}$. (DI PERRI et al. 1991; ANTONUCCI et al. 1995).

Neste estudo a resistência não se mostrou associada a contagem de CD4+, resultado concordante com o encontrado por MURRAY et al. 2000. No entanto, as informações coletas em nosso trabalho ficaram prejudicadas e devem ser observadas com reservas. Por ter um delineamento transversal, este 
estudo avaliou apenas um momento imunológico na história evolutiva dos indivíduos; o exame de contagem de células $\mathrm{CD} 4$ selecionado foi aquele imediatamente anterior ao diagnóstico de $\mathrm{TB}$ e essa informação não esteve disponivel em $24,6 \%$ dos prontuários e nos que apresentaram, o tempo entre o exame de CD4+ imediatamente anterior e o diagnóstico de TB variou de 1 dia a 3 anos. Além disso, sabe-se que os esquemas com drogas anti-retrovirais elevam as taxas de linfócitos $\mathrm{CD} 4+\mathrm{e}$ muitos pacientes que fazem parte do estudo fizeram uso de algum esquema ARV inclusive com inibidores de protease.

A contagem de carga viral do HIV também foi coletada visando avaliar o comprometimento imunológico dos pacientes com TB resistente. Dos 301 casos analisados apenas $97(32,2 \%)$ tinham resultado de exame de carga viral e por este motivo esta variável foi excluída da análise.

Estudos recentes têm demonstrado redução na incidência de doenças oportunistas, incluindo a tuberculose, após a introdução de HAART ou ARV. No entanto, não foi possível analisar o efeito protetor de HAART para o desenvolvimento de TB resistente. $\mathrm{O}$ curto período de seguimento de pacientes que receberam a medicação e o relativamente pequeno número de pacientes tratados com HAART podem ter influenciado na análise desta associação. Estes dados são semelhantes ao de TOLEDO JR et al. 2000 que ao avaliarem fatores de risco para tuberculose em pacientes HIV positivos 
também não encontraram associação entre uso de HAART e não desenvolvimento de TB.

Não houve diferenças estatisticamente significativas entre a proporção de casos de TBMR e TBR em relação ao ano calendário. Não houve também tendência de aumento ou diminuição no número de casos resistentes entre 1993 e 2002 ( dados de 2003 são provisórios e não considerados para esta discussão), embora a proporção de casos de TBR diagnosticados tenha aumentado a partir de 1996 ano em que os exames de cultura e teste de sensibilidade começaram a ser realizados sistematicamente para todos os casos suspeitos de TB/HIV.

O maior tempo de diagnóstico do HIV esteve associado a TB resistente em análise univariada, porém esta variável não se mostrou independentemente associada em análise multivariada. Alguns estudos caso-controle em surtos nosocomiais de TBMR encontraram associação entre o tempo de AIDS e diagnóstico de TBMR. Nos surtos evidenciou-se que o risco de TBMR decorreu de maior exposição a bacilos resistentes e que a imunossupressão teria predisposto os pacientes à manisfestação da TBMR.

Em um estudo recente realizado na Europa, o risco de desenvolver tuberculose, independentemente da contagem de células CD4, mostrou-se alto tanto nos pacientes com 4 a 6 anos de diagnóstico de HIV como naqueles que 
apresentaram TB depois de mais de 9 anos de diagnóstico de HIV (VAN ASTEN et al 2003).

Em nosso estudo o tempo de diagnóstico de HIV mostrou-se associado a contagem de células $\mathrm{CD} 4$ menor que 200 células $/ \mathrm{mm}^{3}$; no entanto não houve associação entre essas variáveis e TBR independentemente de história de tratamento anterior com drogas anti-tuberculose e por isso foram excluídas do modelo final.

Como relatado na literatura (ISEMAN e MADSON 1989; BRUDNEY e DOBKIN 1991; FRIEDEN et al. 1993; SALOMON et al. 1994; WHO 2000; ESPINAL et al 2001), em nossa casuística, a varíavel que se mostrou independetemente associada a tuberculose resistente foi tratamento anterior com tuberculostáticos.

\section{3- Análise de causa de óbito}

Dos 111 pacientes que faleceram, durante o seguimento de estudo, foi possivel verificar a causa de morte em $99(89,2 \%)$ óbitos.

Em apenas um óbito a TB foi mencionada como causa básica de morte, no entanto, o HIV/AIDS não foi citado em nenhum campo desta declaração de óbito. 
A não ocorrência de $\mathrm{TB}$ como causa básica, nos óbitos em que há mencão da doença, se deve às disposições da Classificação Internacional das Doenças (CID-10) as quais incorporaram o conhecimento atualizado da etiopatogenia da AIDS e que privilegiam esta última como causa básica (OMS 1993). Dentre tais disposições, a que interpreta serem as doenças infecciosas, em particular as doenças oportunistas, conseqüentes à AIDS, determinou o deslocamento da TB para condição de causa associada naquelas mortes em que a AIDS estivesse presente (SANTO et al. 2003)

Em nosso estudo a TB foi mencionada como causa associada de morte em apenas $49(49,5 \%)$ óbitos. Das 50 declarações de óbito em que não há menção de tuberculose 37 (74\%) apresentaram em seus prontuários diagnóstico de TB ativa no momento do óbito.

Em um estudo realizado na cidade de Nova Iorque em 1992, 310 pessoas foram identificadas no registro de casos de TB como tendo a doença ativa no momento do óbito. Desses apenas $104(34 \%)$ tiveram a tuberculose mencionada no atestado de óbito. Segundo os autores, os indivíduos HIV positivos apresentaram risco maior do que os indíduos com sorologia negativa para o HIV de ter a TB omitida de seus atestados (WASHKO e FRIEDEN 1996).

Estes fatos comprometem as estatísticas de mortalidade por subestimar a tuberculose como causa de morte. No Estado de São Paulo, em 1983, cerca de $78 \%$ das menções de tuberculose em declarações de óbito como causa de 
morte foram identificadas como causa básica (SANTO 1988). Ao passo que no ano de 1998 este valor foi de 54,2\% (SANTO et al. 2003).

\section{4- Limitações do estudo}

Este estudo apresenta várias limitações, principalmente por ter sido baseado em dados secundários. Dos 343 casos levantados não foi possível encontrar o prontuário de 34 pacientes. Dentre estes casos, 5 eram resistentes e 29 sensíveis. Se estes pacientes fossem incluídos no estudo, a resistência seria de $18,6 \%$ o que demonstra que embora tenha sido grande o número de prontuários não encontrados a amostra não ficou subestimada em taxa de resistência.

O instrumento de coleta de dados foi elaborado para atender as necessidades dos objetivos da pesquisa; porém os prontuários apresentaram peculiaridades e dificuldades que limitaram o preenchimento do formulário no tocante à padronização, formato e ausência de informações importantes.

Um estudo epidemiológico com dados secundários num serviço de saúde geralmente possibilita uma redução dos custos da investigação, pois os dados foram previamente colhidos. Por outro lado, aumenta a possibilidade de ocorrência de erros devido à falta de sistematização na coleta de dados (KELSEY et al. 1996). Observando-se os prontuários dos pacientes, alguns itens eram assinalados apenas em caso de informação afirmativa (como foi o 
caso da informação sobre presídio e hospitalização prévia), dificultando a codificação ou, por falta de informação fazendo com que algumas variáveis fossem retiradas da análise. Optou-se pela exclusão daquelas variáveis que apresentaram mais de $50 \%$ dos casos sem informação como: contagem de carga viral imediatamente anterior ao diagnóstico de TB e história de reclusão em presídios antes do diagnóstico.

Apesar da limitações, este estudo aponta elevados índices de resistência às drogas tuberculostáticas entre indivíduos HIV positivos da Baixada Santista.

$\mathrm{O}$ presente trabalho aponta ainda a necessidade de estudos complementares do tipo prospectivo e multicêntricos que melhor avaliem o perfil de resistência e os fatores predisponentes a tuberculose resistente em indivíduos HIV positivos, principalmente na Baixada Santista que é região prioritária no controle da tuberculose e AIDS . 


\section{6- Conclusões}

- A resistência a uma ou mais drogas foi diagnosticada em 18,9\% dos casos (57 pacientes), sendo que $10,6 \%$ (32 pacientes) apresentaram resistência a pelo menos isoniazida e rifampicina;

- A resistência adquirida foi observada em $70 \%$ dos casos;

- No período de estudo, de janeiro de 1993 a março de 2003, observou-se manutenção da proporção de casos resistentes às drogas entre os casos TB/HIV estudados;

- Não foi demonstrada associação entre a presença de resistência às drogas antituberculose e as variáveis: sexo, idade, uso de drogas injetáveis, uso de álcool, falta de domicílio, contagem de células $\mathrm{CD} 4+$ no momento do diagnóstico de TB e uso de medicamentos anti-retrovirais;

- Em análise univariada, internação prévia ao diagnóstico de TB, tempo de diagnóstico de HIV maior do que 5 anos e tratamento anterior com tuberculostáticos mostraram-se associados a tuberculose resistente ;

- Em análise multivariada apenas tratamento anterior com tuberculostático, quando ajustado pela faixa etária, mostrou-se independentemente associado a tuberculose resistente $(\mathrm{OR}=5,49 ; \mathrm{IC} 95 \% 2,60-11,60)$;

- Entre os 99 casos em que foi possível verificar a causa de óbito, a TB foi mencionada em apenas $49(49,5 \%)$ dessas mortes. 
- Apesar das limitações de um estudo que utiliza dados secundários este trabalho mostrou a relevância da resistência em pacientes HIV positivos na região da Baixada Santista. 


\section{7 - Referências}

Ackah A, Coulibaly D, Digbeu H, Diallo K, Vetter K, Coulibaly I, Greenberg A, De Cock K.Response to treatment, mortality, and CD4 lymphocyte counts in HIV-infected persons with tuberculosis in Abidjan, Côte d'Ivoire. Lancet 1995 345:607-610.

AIDSCAP/Family Health International, Harvard School of Public Health y UNAIDS. Informe final del simpósio sobre el Estado y tendencias de la pandemia mundial del VIH/SIDA. In: Conferencia Internacional sobre el SIDA, 11, Vancouver, Canadá, 1996. Arlington, Virginia, 1996: 69.

Almeida da Silva PE, Osório M, Reinhardt MC, Fonseca LS, Delladostin AO. Drug resistance of strains of Mycobacterium tuberculosis isolated in Brazil. Microbes and Infection 2001, 1111-1113.

Antonucci G, Girardi E, Raviglione M, Ippolito G. Risk factors for Tuberculosis in HIV persons. A porspective cohort study. JAMA 1995; 274:143-148

Badri M, Wilson D, Wood R. Effect of highly active antiretroviral therapy on incidence of tuberculosis in South Africa: a cohort study. Lancet 2002;359:2059-2064.

Banerjee A, Dubnau E, Ouernard A . inhA, a gene enconding a target for isoniazid and ethionamide in Mycobaterium tuberculosis. Science 1994; $263: 227-230$

Baptista IMFD, Oelemann MC, Opromolla DVA, Suffys PN. Drug Resistance and Genotypes of Strains of Mycobacteriumtuberculosis Isolated from Human Immunodeficiency Virus-infected and Non-infected Tuberculosis Patients in Bauru,São Paulo, Brazil. Mem Inst Oswaldo Cruz 2002, 97(8): 1147-1152

Barnes PF, Bloch, AB, Davidson PT, Snider DE Jr. Tuberculosis in patients with human immunodeficiency virus infection. N Engl J Med 1991; $324: 1644-1650$

Barnes PF, Barrows SA . Tuberculosis in the 1990s.Ann Intern Med 1993 119: 400-410.

Barreto AM, Martins FM. Estudo da resistência primária no Brasil no período de 1986 a 1988. Bol Campanha Nac Contra a Tuberc 1988, 2:21-25. 
Barroso EC, Rodrigues JLN, Pinheiro VGF, Campelo CL. Prevalência da tuberculose multirresistente no Estado do Ceará, 1990-1999. J Pneumol 2001;27(6):310-314

Beck-Sagué C, Dooley SW, Hutton MD, Otten J, Breeden A, Crawford JT, Pitchenik AE, Woodley C, Cauthen G, Jarvis WR. Hospital outbreak of multidrug-resistant Mycobacterium tuberculosis infections. JAMA 1992;268:1280-1286.

Berning SE, Huitt GA, Iseman MD, Peloquim CA . Malabsorption of antituberculosis medications by a patient with AIDS. N Engl J Med 1992;327:1817-1818.

Bloch A, Cauthen GM, Onorato ID, Dansbury KG, Kelly GD, Driver CR, Snider DE Jr. Nationwide survey of drug-resistant tuberculosis in the United States. JAMA 1994;271:665-671.

Bradford WZ, Martin JN, Reingold AL, Schecter GF, Hopewell PC, Small $\mathrm{PM}$. The changing epidemiology of adquired drug-resistant tuberculosis in San Francisco, USA. Lancet 1996; 348:928-931.

Braun MM, Kilburn JO, Smithwick RW, Coulibaly IM, Coulibaly D, Silcox VA, Gnare E, Adjorlolo G, Cock KM. Hiv infection and primary resistance to antituberculosis drugs in Abidjan, Côte d'Ivore. AIDS 1992; 6:1327-1330.

Brito AM, Castilho EA, Szwarcwald CL. R.ev Soc Bras Med Trop 2001; 34(2):207-217

Brodt HR, Kamps BS, Gute P, Knupp B, Stazewski S, Helm EB. Changing incidence of AIDS-defining illnesses in the era of antiretroviral combination therapy. AIDS 1997;11:1731-1738

Brudney K., Dobkin J. Resurgent tuberculosis in New York City, human immunodeficiency virus, homeless and the decline of tuberculosis control programme. Am Rev Respir Dis 1991; 144:745-749.

Canetti G, Fox W, Khomenko S, Mahler HT, Menon NK, Mitchison DA, Rist $\mathrm{N}$, Smelev NA. Advances in techiniques of testing mycobaterial drug sensitivity tests in tuberculosis programmes. Bull WHO 1969;41:21-43

Catwell MF, Snider DE, Cauthen GM, Onorato IM. Epidemiology of tuberculosis in the United States, 1985 through 1992. JAMA 1994; 272:535539 
Center for Disease Control and Prevention. Screening for tuberculosis and tuberculous infection in high-risk populatuions and the use of preventive therapy for tuberculosis infection in the United States. Recomendations of the Advisory Committe for elimination of Tuberculosis.MMWR1990;39(8):1-12

Center for Disease Control and Prevention. Nosocomial transmission of multidrug-resistant tuberculosis among infected persons - Florida and New York, 1988-1991. MMWR 1991;40:585-591

Center for Disease Control and Prevention.Initial therapy for tuberculosis in the era of multidrug resistance. MMWR 1993;42:1-4.

Center for Disease Control and Prevention. Guidelines for preventing the transmission of Mycobacterium tuberculosis in health-care facilities, 1994.MMWR 1994;41:nRR-13.

Center for Diseases Control and Prevention. Tuberculosis morbidity- United States 1997. MMWR 1998; 47:253-257.

Centro de Vigilância Epidemiológia. Divisão de Tuberculose. Casos novos de TB por forma clínica e faixa etária - 2003 [on line]. Disponível em $<$ URL:http://www.cve.sp.gov.br/htm/tb/tb_cn03.htm> [2004 nov 3]

Chin J, Mann J. Global surveillance and forecasting of AIDS. Bull WHO 1989; 67:1-7.

Cohn DL, Bustreo F, Raviglione MC. Drug-resistant tuberculosis: review of the worldwide situation and the WHO/IUATLD Global Surveillance Project. Clin Infect Dis 1997; 24 (suppl 1):121-130.

Cole ST, Telenti A .Drug resistance in Mycobacterium tuberculosis. Eur Respir J 1995; 8:701s-713s

Collins $\mathrm{CH}$, Grange JM, Yates MD. Drug susceptibility tests. IN: Tuberculosis bacteriology: organization and practice, 2 ed. Oxford, Butterworths Heinimann 1997;98

Corbett EL, Churchyard GJ, Charalambos S. Morbidity and mortality in South African gold miners: impact of untreated HIV infection. Cli Infect Dis 2002; 34:1251-1258.

Corbett EL, Watt CJ, Walker N, Maher D, William BG, Raviglione MC, Dye C. The Growing Burden of Tuberculosis. Arch Intern Med 2003; 163:10091021 
Crofton J. Tuberculosis undefeated. Br Med J1960;ii:679-687.

Daley CL, Small PM, Schecter GF, et al. An outbreak of tuberculosis with acelerated progression among persons infected with the human immunodeficiency virus. N Engl J Med. 1992; 326:231-235.

David HL. Probability distribution of drug resistant mutants in unselect populations of Mycobacterium tuberculosis. Appl Microbiol 1970;20:810814

Dean AG, Dean JÁ, Burton AH, Dicker RC. Epi Info version 6.04 : a word processing, data base and statistics program for epidemiology microcomputers. Atlanta, Centers for Disease Control and Prevention, 1997

Di Perri G, Vento S, Cruciani M, Micciolo R, Concia E, Bassetti D. Tuberculosis and HIV infection. N Engl J Med. 1991;325:1882-1883.

Dolin PJ, Raviglione MC, Kochi A. Global tuberculosis incidence and mortality during 1990-2000. Bull WHO 1994; 72:213-220

Dye C, Scheele S, Dolin P, Pathania V, Raviglione MC; for the WHO Global Surveillance and Monitoring Project. JAMA 1999 ;282: 677- 686

Dye C, Watt, CJ, Bleed D. Low access to a highly effective therapy: achallenge for internacional tuberculosis control. Bull WHO 2002; 80:437444

Dylewski J, Thibert L. Failure of tuberculosis chemotherapy in a human immunodeficiency virus-infected patient. J Infect Dis 1990; 162:778-779.

Edlin BR, Tokars JI, Grieco MH, Crawford JT, Williams J, Sordello EM, ONG KR, Kilburn, JO, Dooley SW, Castro KG, Jarvis, WR, Hoemberg SD. An outbreak of multidrug- resistant tuberculosis among hospitalized patients with the acquired immunodeficiency syndrome. N. Engl J Med 1992; 326:1514- 1521 .

Ellner JJ. Review: The imune response in human tuberculosis-Implications for tuberculosis control. J Infect Dis 1997;176:1351-1359

Espinal MA, Laserson K, Camacho M, Fuscheng Z, Kim SJ, Tladi RE, Smith I, Suarez P, Antunes ML, George AG, Martin-Casabona N, Simelane P, Weyer K, Binkin N, Raviglione MC. Determinants of drug-resistant 
tuberculosis: analysis of 11 countries. Int $\mathbf{J}$ Tuberc Lung Dis 2001;5(10):885-886

Fandinho FCO, Kritski Al, Hofer C, Conde Jr H, Ferreira RMC, Silva MG, Fonseca LS. Drug resistance patterns among hospitalized tuberculous patients in Rio de Janeiro, Brazil, 1993-1994. Mem Inst Oswaldo Cruz 1999; 94(4):543-547

Fische MA, Uttamchandan RB, Daikos GL, Poblete RB, Moreno JN, Reyes R R, Boota AM, Thompson LM, Cleary TJ, Lai S. An outbreak of tuberculosis caused by multipledrug- resistant tubercle bacilli among pacients with HIV infection. Ann Intern Med 1992; 117:177- 183.

Fischl MA, Uttamchandani RB, Daikos GL, Poblete RB, Moreno JN, Reyes RR, Boota AM, Thompson LM, Cleary TJ, Lai S. Na outbreak of tuberculosis caused by multiple-drug-resistant tubercle baccili among patients with HIV infection. Ann Int Med 1992 117(3):177-183

Fox W. Estado actual de la quimioterapia acortada de la tuberculosis. Boletín de la Unión Internacional Contra La Tuberculosis 1978;53:278-291.

Frieden TR, Sterling T, Mendez AP, Kilburn JO, Cauthen GM, Dooley SW. The emergence of drug- resistant tuberculosis in New York City. $\mathbf{N}$ Engl $\mathbf{J}$ Med 1993 ;328:521-526.

Frieden TR, Sherman LF, Maw KL, Fujiwara PI, Crawford JT, Nivin B, Sharp V, Hwlett JR, Brudney K, Alland D, Kreiswirth BN. A multi- institutional outbreak of highly drug- resistant tuberculosis -Epidemiology and clinical outcomes. JAMA 1996; 276, n. 15:229-235.

Friedman CR, Stoeckle MY, Kreiswirth BN, Johnson WD, Manoach SM, Berger J, Sathianthan K, Hafner A, Riley LW. Transmission of multidrugresistant tuberculosis in a large urban setting. Am J Respir Crit Care Med $1995 ; 152: 355-359$.

García MR, Gómez JL, Sancho MC, Álvarez RA, Zacarias F, Amor JS. Epidemiology of AIDS and tuberculosis. Bulletin of PAHO 1995 29(1): 37 58

Girardi E, Antonucci G, Vanacore P, Libanore M, Errante I, Matteelli A, Ippolito G. Impact of combination antiretroviral therapy on the risk of tuberculosis among persons with HIV infection. AIDS 2000, 14:1985-1991. 
Gomes C, Rovaris DB, Severino JL, Gruner MF. Perfil de resistência de "M. tuberculosis"isolados de pacientes portadores do HIV/AIDS atendidos em um hospital de referência. J Pneumol 2000;26(1):25-29.

Gordin FM, Nelson ET, Matts JP, Cohn PL, Ernest J, Benator D, Berch CL, Crane LR, Sampson JH, Bragg PS, El Sadr W. The impact of human immunodeficiency virus infection on drug- resistant tuberculosis. Am J Respir Crit Care Med 1996; 154:1478- 1483.

Grange JM, Winstanley PA, Davies PD. Clinically significant drug interactions with antituberculosis agents. Drug Saf 1994 11:242-251

Hall HI, Song R, Mckenna MT. Increses in HIV diagnoses - 29 States, 19992002. MMWR 2003; 52(47):1145-1148

Hannan MM; Peres H; Maltez F; Hayward AC; Machado J; Morgado A; Proenca R; Nelson MR; Bico J; Young DB; Gazzard BS. Investigation and control of a large outbreak of multi-drug resistant tuberculosis at a central Lisbon hospital. J Hosp Infect 2001; 47(2):91-97

Hijjar MA. Epidemiologia da Tuberculose no Brasil. Inf Epidemiol SUS 1992; 6:53-81.

Hijjar MA, Oliveira MJPR, Teixeira GM. A Tuberculose no Brasil e no mundo. Boletim de Pneumologia Sanitária 2001; 9 n.2- jul/dez.

Hosmer JR, Lemeshow S. Applied logistic regression. New York. John Wiley and Sons, 1989

Iseman MD, Madsen LA. Drug- resistant tuberculosis. Clin Chest Med 1989: 10: 341-353.

Jones JL, Hanson DL, Dworkin MS. Surveillance for AIDS-defining opportunistic illnesses, 1992-1997. MMWR 1999;48:1-22.

Kantor IN. Bacteriologia de la tuberculosis humana y animal. Martinez, Centro Panamericano de Zoonosis, 1988. (serie de Monografias Científicas y técnicas. 11/Rev.I)

Kaye K, Frieden TR. Tuberculosis control: the relevance of classic principles in an Era of AIDS and multidrug resistance. Epidemiol Rev1996; 18 :52-63 
Keizer ST, Langendam MM, Van Deutekom H. How does tuberculosis relate to HIV positive and HIV negative drug users? J Epidemiol Community Health2000:54(1):64-68

Kelsey JL, Whitemore AS, Evans AS, Thompson WD. Methods in obervational epidemiology. New York, Oxford University Press, 1996

Kent JK. The epidemiology of multidrug-resistant tuberculosis in the United States. Med Clin N Am 1993;77:1391-1409

Kirk O, Mocroft A, Katzenstein TL. Changes in use of antiretroviral therapy in regions of Europe over time. AIDS 1998;12:2031-2039

Kochi A, Vareldzis B, Styblo K. Multidrug-resistant tuberculosis and its control. Res Microbiol 1993;144:104-110.

Lee BL, Safrin S. Interactions and toxicities of drugs used in patients with AIDS. Clin Infect Dis 1992;14:773-779.

Lee SK, Tan KK, Chew SK, Snodgrass I. Multidrug-resistant tuberculosis. Ann Acad Med Singapore 1995; 24: 442- 446.

Leowski J, Miller m. Tuberculosis and AIDS: European and worldwide perspectives. Soz Präventivmed 1992; 37:199-206

Liu Z, Shilkret KL, Finelli L. Epidemiology of drug-resistant tuberculosis in New Jersey from 1991 to 1995. Int J Epidemiol 1998;27:121-126.

Lourenço MCS, Silva MG, Fonseca LS. Multidrug-Resistant Tuberculosis Among Male Inmates In Rio De Janeiro, Brazil. Brazilian Journal of Microbiology 2000; 31:17-19

Luftey M, Della-Latta P, Kapur V. Independent origin of mono-rifampinresistant Mycobaterium tuberculosis in patients with AIDS. Am J Resp Crit Care Med 1996 153:837-840

Machado ES, Cruz ML, Souza MJ, Ribeiro S, Silva MG, Giordani ML, Guimarães. Drug-resistant tuberculosis in HIV+ and HIV- patients. IN: Internacional Conference on AIDS, 10; Internacional Conference on STD, 5; Yokohama, 1994. Abstracts. Yokohama,1994, p.168 
Maher D, Mikulencak M. What is DOTS? A guide to understanding the WHO- recommended TB control strategy known as DOTS. WHO/CDS/CPC/TB 1999

Mantel. Chi-square tests with one degree of freedom: extensions of the Mantel-Haenszel procedure. J Am Stat Ass 1963;58:690-700

Magarão MF, Fraga H, Dauster J, Santiago AC, Almeida AP. Informação sobre a freqüência da resistência do Mycobacterium tuberculosis às drogas standard no Rio de Janeiro entre 1958 e 1966. R.ev Serv Nac Tuberculose 1967;11:435-496

March F, Garriga X, Rodríguez P, Moreno C, Garrigó M, Coll P, Prats G. Adquired drug resistance in Mycobacterium tuberculosis isolates recovered from compliant patients with human immunodeficiency virus - associated tuberculosis. CID 1997;25:1044-1047

McDonald LC, Archibald LK, Rheanpumikankit S. Unrecognised Mycobacterium tuberculosis bacteremia among hospital inpatients in less developed countries. Lancet 1999;354:1159-1163.

McNaughten AD, Hanson DL, Jones JL. Effects of antiretroviral therapy and opportunistic illness primary chemoprophylaxis on survival after AIDS diagnosis. AIDS 1999; 13:1687-1695

Mduli K, Slaydon RA, Zhu Y. Inhibition of a Mycobaterium tuberculosis betaketoacyl ACP synthase by isoniazid. Science 1998;280:1607-1610.

Medical Research Council .Prevention of streptomycin resistance by combined chemotherapy; a Medical Research Council investigation. Br Med J. $1952 ; 1: 1157-62$.

Melo FAF, Afiune JB, Ribeiro LHG, Felice EAA, Catelo A . Resistência primária do "M. tuberculosis" num serviço ambulatorial de referência em São Paulo: evolução por três décadas e comparação com outros estudos nacionais.

J Pneumol 1996;22(1):3-8

Melo FAF , Afiune JB , Neto J I, Almeida EA , Spada DTA ,Antelmo ANL, Cruz ML. Aspectos epidemiológicos da tuberculose multirresistente em serviço de referência na cidade de São Paulo. Revista da Sociedade Brasileira de Medicina Tropical 2003 36(1):27-34 
Ministério da Saúde. Coordenção Nacional de Pneumologia Sanitária, Sociedade Brasileira de Pneumologia e Tisiologia. I Conseso Brasileiro de Tuberculose - 1997. J Pneumologia 1997; 23:281- 342

Ministério da Saúde . Fundação Nacional de Saúde. Guia das Doenças ;19992000

Ministério da Saúde. Boletim Epidemiológico AIDS. Ano XV n $\mathrm{n}^{\circ} 01-48^{\circ} / 2002$ Semanas epidemiológicas -outubro de 2001 a março de 2002. ISSN 15171159 .

Ministério da Saúde. Boletim Epidemiológico AIDS. Ano XVII n01-01 à 52 Semanas epidemiológicas -janeiro a dezembro de 2003. ISSN 1517-1159.

Mitchison DA, Dickinson JM. Mecanismos bactecidas en la quimioterapia de corta duracion. Boletín de la Unión Internacional Contra La Tuberculosis 1978;53:263-268

Mitchison DA. Drug resistance in mycobateris. Br Med Bull 1984;40:84-90

Mocroft A, Vella S, Benfield TL, Chiesi A, Miller V, Gargalianos P. Changing patterns of mortality across Europe in patients infected with HIV- 1. Lancet 1998;352:1725-1729.

Monno L, Angarano G, Carbonara S. Emergence of drug-resistant Mycobacterium tuberculosis in HIV-infected patients. Lancet 1991;337-852

Moro ML; Gori A; Errante I; Infuso A; Franzetti F; Sodano L; Iemoli E An outbreak of multidrug-resistant tuberculosis involving HIV-infected patients of two hospitals in Milan, Italy. Italian Multidrug-Resistant Tuberculosis Outbreak Study Group. AIDS 1998; 12(9):1095-1102.

Munsiff SS, Joseph S, Ebrahimzadeh A, Frieden TR. Rifampin-monoresistant tuberculosis in New York city, 1993-1994. Clin Infect Dis 1997 25: 14651467

Murray CJL, Stylbo K, Rouillon A. Tuberculosis in developing countries: burden, interventions and cost. Bull Int Un Tuberc Lung Dis. 1990; 85:1-19.

Murray J, Sonnenberg P, Shearer S, Godfrey-Faussett P. Drug-resistant pulmonary tuberculosis in a cohort of southern African goldminers with a high prevalence of HIV infection. S Afr Med J. 2000; 90(4):381-386. 
Nachega JB, Chaisson RE. Tuberculosis Drug Resistance: A Global Threat. CID 2003;36(suppl 1)S24-S30

Narain JP, Raviglione MC, Kochi A. HIV- associated tuberculosis in developing countries; epidemiology and strategies for prevention. Tubercle and Lung Disease $1992 ; 73: 311-321$

Natal S, Valente JG, Sánchez AR, Penna MLR. Resistência a isoniazida e rifampicina e história de tratamento anterior para tuberculose. Cad. Saúde Pública 2003; 19:1277-1281

Nunn P, Elliott AM, McAdam KP. Impact of human immunodeficiency virus on tuberculosis on developing countries. Thorax 1994 49: 511-518.

O'Brien RJ. Drug-resistant tuberculosis: etiology, management and prevention. Semin Respir Med 1994; 9:102-104.

Organização Mundial da Saúde. Classificação estatística internacional de doenças e problemas relacionados à saúde: $1^{\mathbf{a}}$ revisão. São Paulo: Centro Colaborador da OMS para Classificação de Doenças em Português. EDUSP;1993. v.1

Ortega FP, Rivera JMPS, Garcia RR, Garcia JG, Pérez-Herrero JRC, Rodriguez JJV, Pérez-Medel AP. Factores predictivos del abandono del tratamiento antituberculoso en pacientes infectados por el virus de la inmunodeficiencia humana. R.ev Clin Esp 1997;197:163-166

Pablos-Mendez A, Raviglione MC, Laszlo A, Binkin N, Rieder HL, Bustreo F, Cohn DL, Lambregts-van Weezenbeek CS, Kim SJ, Chaulet P, Nunn P. Global surveillance for antituberculosis-drug resistance, 1994-1997. World Health Organization-International Union against Tuberculosis and Lung Disease Working Group on Anti-Tuberculosis Drug Resistance Surveillance. N Engl J Med. 1998 ;338(23):164 1-1649

Pablos-Méndez A, Gowda DK, Frieden TR. Controlling multidrug-resistant tuberculosis and access to expensive drugs: a rational framework. Bull WHO 2002;80(6):489-495.

Palella FJ Jr, Delaney KM, Moorman. Declining morbidity and moartlaity among patients with advanced human immunodeficiency virus infection. $\mathbf{N}$ Engl Med 1998;338:853-860

Parsons LM, Driscoll JR, Taber HW, Salfinger M. Drug resistance in tuberculosis. Infect Dis Clin N Am 1997;11:905-927 
Patel KB, Belmonte R, Crowe HM. Drug malabsorption and resistant tuberculosis in HIV-infected patients. N Engl J Med 1995 323(5):336-337

Peloquim CA, MacPhee AA, Berning SE. Malabsorption of antimycobacterial medications. N Engl J Med 1993;329:1122-1 123.

Perlman DC, Salomon N, Perkins MP, Yancovitz S, Paone D, Des Jarlais DC. Tuberculosis in drug users. Clin Infect Dis 1995;21:1253-1264

Pinto, W P. Tuberculose e resistência a drogas em pacientes atendidos em um centro de referência para síndrome da imunodeficiência adquirida em São Paulo - Brasil. São Paulo, 1998. Tese(Doutorado) - Faculdade de Medicina da Universidade de São Paulo.

Pitchenik AE, Cole C, Russel B, Fischl M, Spira D. Tuberculosis, atypical micobacteriosis and acquired immunodeficiency syndrome among Haitian and on-Haitian patients in South Florida. Ann Inter Med. 1984; 101:641-645

Pyle MM. Relative numbers of resistant tubercle bacilli in sputum of patients before and during treatment of streptomycin. Proc Staff Meetings Mayo Clinic 1947;22:465.

Reichman LB. The challenge of drug-resistant tuberculosis. Cleve Clin J Med 1994; 61:431-437.

Reider HL, Cauthen GM, Comstock GW, Snider DE Jr. Epidemiology of tuberculosis in the United States. Epidemiol Rev 1989; 11:79-98

Rieder HL. Epidemiology of tuberculosis in Europe. Eur Respir J 1995; 8 suplement 20:20-32

Ritacco V; Di Lonardo M; Reniero A; Ambroggi M; Barrera L; Dambrosi A; Lopez B; Isola $\mathrm{N}$; de Kantor IN. Nosocomial spread of human immunodeficiency virus-related multidrug-resistant tuberculosis in Buenos Aires. J Infect Dis 1997; 176(3):637-642.

Rosemberg J, Waisbich E, Passos Filho MCR. Resistência primária em 906 casos de tuberculose pulmonar provenientes de diversas regiões do Brasil. R.ev Serv Nac Tuberculose 1967;11:311-333

Rossetti MLR, Valim ARM, Silva MSN, Rodrigues VS. Tuberculose resistente : revisão molecular. Rev Saúde Pública 2002; 36(4) 525- 532. 
Rothman KJ, Greenland S. Modern Epidemiology $2^{\mathbf{a}}$ edição. LippincottRaven ;1998

Rufino-Netto, A . Tuberculose: a calamidade negligenciada. Revista da Sociedade Brasileira de Medicna Tropical 2002; 35(1):51-58

Rüsch-Gerdes S. Epidemiology of resistant tuberculosis in Europe. Infection 1999; 27 Suppl 2:S17-8

Salomon N, Perlman DC, DePalo VA, Kolokathis A, Wilets I. Drug-Resistant Tuberculosis: Factores Associated with Rise in Resistance in na HIV-infected Urban Population. The Mount Sinai Journal of Medicine 1994;61:341-348.

Sandman L, Schluger NW, Davidow AL, Bonk S. Risk factors for rifampinmonoresistant tuberculosis: A case-control study. Am J Respir Crit Care Med 1999; 159:468-472.

Santo, AH. Causas múltiplas de morte: formas de apresentação e métodos de análise[tese de doutorado]. São Paulo. Faculdade de Saúde Pública da Universidade de São Paulo; 1998

Santo AI, Pinheiro CE, Jordani MS. Causas múltiplas de morte associadas à tuberculose no Estado de São Paulo, 1998. Rev. Saúde Pública 2003;37(6):714-721

Santoro-Lopes G, Pinho AMF, Harrison LH, Schechter M. Reduced risk of tuberculosis among brazilian patients with advanced human immunodeficiency virus infection treated with highly active antiretroviral therapy. CID 2002;34:543-546.

Schwoebel V, Dicludt B, Binoist A, Haeghebaert S, Torrea G, Vincent V, Grosset J. Multidrug resistant tuberculosis in France 1992-4: two case- control studies. BMJ 1998 - vol. 317

Secretaria de Estado da Saúde. A Tuberculose no Estado de São Paulo. Informe Técnico- Campanha Estadual de Busca de Tuberculose. Orientações Operacionais 2000

Senya C, Mehta A, Harwell JI, Pugatch D, Flanigan T, Mayer KH. Spectrum of opportunistic infections in hospitalized HIV-infected patients in Phnom Penh, Cambodia. Int J STD AIDS 2003 14(6):411-416. 
Shafer RW, Chirgwin KD, Glatt Ae, Dahdouh MA, Landesman SH, Suster B. HIV prevalence, immunosuppression and drug resistance in patients with tuberculosis in na area endemic for AIDS. AIDS 1991;5:399-405.

Shimao T. Drug resistance in tuberculosis control. Tubercle 1987; 68(suppl) 5- 15 .

Silva EAM, Sato DN, Telles MAS, Martins MC, Palaci M, UEKI SYM. Perfil de resistência de Mycobacterium tuberculosis no Estado de São Paulo, 1986 a 1990. R.ev Inst Adolfo Lutz 1992;52:37-40

Small PM, Schecter GF, Goodman PC, Sande MA, Caisson RE, Hopewell PC. Treatment of tuberculosis in patients with advanced human immunodeficiency virus infection. N Engl J Med 1991; 324:289-294

Small PM, Shafer RW, Hopewell PC. Exogenus reinfection with drugresistant Mycobaterium tuberculosis in patients with advanced HIV infection. N Engl J Med 1993;328:1137-1144.

Snider DE Jr, Cauthen GM, Farer LS, Kelly GD, Kilburn JO, Good RC, Dooley SW. Drug-resistant tuberculosis (letter). Am R.ev Respir Dis 1991; 144:732

Snider DE, Roper WL. The new tuberculosis. N Engl J Med 1992; 32:106110.

Spellman CW, Matty KJ, Meis SE. A survey of drug- resistant Mycobacterium tuberculosis and its relationship to HIV infection. AIDS 1998; 12: 191- 195

Statacorp. Stata statistical software; realease 4.0. Collefe Station, Stata Corporation, 1995

Stylbo K. The impact of HIV infection on the global epidemiology of tuberculosis. Bull Int Un Tuberc Lung Dis 1991; 66: 27-32.

Toledo Jr. ACC, Greco DB,Antunes CMF. Risk Factors for Tuberculosis among HumanImmunodeficiency Virus-infected Persons. A Case-control Study in Belo Horizonte, Minas Gerais,Brazil (1985-1996).Mem Inst Oswaldo Cruz 2000 95: 437-443

Toman K. Tuberculosis case-finding and chemotherapy: questios and answers. Geneva, WHO 1979. 
Toman K. Tuberculosis, detection de casos y quimioterapia. Preguntas e respuestas. Washington D.C. Organizacion Paramericana de la Salud 1980. (Publi. Cient. 392)

Torres L, Arazo P, Blas Perez J, del Pilar Amador M, Antonia Lezcano M, Jose Revillo M, Bautista Garcia-Moya J. Resistance of Mycobacterium tuberculosis in Zaragoza, Spain (1993-1997) and related factors.Med Clin (Barc). 2000; 115(16):605-9.

UNAIDS. AIDS epidemic update: 2003.

Vall Mayans M, Maguire A, Miret M, Alcaide J, Parrón I, Casabona J. The spread of AIDS and the re-emergence of tuberculosis in Catalonia, Spain. AIDS 1997;11:499-505

van Asten L, Langendam M, Zangerle R, Hernandez Aguado I, Boufassa F, Schiffer V, Brettle RP, Robertson JR, Fontanet A, Coutinho RA, Prins M. Tuberculosis risk varies with the duration of HIV infection: a prospective study of European drug users with known date of HIV seroconversion. AIDS. 2003; 17(8):1201-1208.

Vareldzis BP, Grosset J, Kantos I, Crofton J, Laszlo A, Felten M, Raviglione MC, Kochi A. Drug-resistant tuberculosis: laboratory issues. Tubercle and lung disease 1994; $75: 1-7$.

Washko RM, Frieden TR. Tuberculosis surveillance using death certificate data, New York City, 1992. Public Health Reports 1996;111:251-255

Weissler JC. Southestern Internal Medicine Conference: TuberculosisImunopathogenesis and therapy. Am J Medical Sciences 1993;305:52-64

Werneck-Barroso E, Vieira MAMS, Almeida LH, Carvalho CES, Teixeira AK, Gontijo PP, Kristski AL. Tuberculosis and drug resistance in HIV infectde patients in Brazil: a prospective study. In: Internacional Conference on AIDS, 9; Internacional Conference on STD, 4; Berlim, 1995. Abstracts. Berlin, 1995, p.327

Whalen C, Lahart C, Hom D, Simberkoff M, Ellner J, Horsburg C. Accelerated clinical course of HIV infection after tuberculosis. Am J Respir Crit Care Med 1995; 151:129-135

Whalen CC, Nsubaga P, Okwerea A . Impact of pulmonary tuberculosis on survival of HIV-infected adults: aprospective epidemiologic study in Uganda. AIDS 2000;14:1219-1228 
World Health Organization and Global Tuberculosis Programme International Union Against Tuberculosis and Lung Disease (IUATLD). Guidelines for surveillance of drugs resistance in tuberculosis. Geneva, WHO; Paris, IUATLD, 1997.

World Health Organization. Anti-tuberculosis drug resistance in the world: the WHO/IUATLD global project on antituberculous drug resistance surveillance 1994-1997. WHO/TB/97,229. Geneva: World Health Organization, 1997a.

World Health Organization. Global AIDS surveillance. Weekly Epidemiological Record - Relevé ëpidemiologique Hebdomadaire 1998; 26:193-197

World Health Organization/IUATLD. Global Project on Anti-tuberculous Drug Resistance Surveillance: Report 2: Prevalence and trends. Geneva: World Health Organization, 2000.

World Health Organization. Tuberculosis. Fact Sheet n ${ }^{\circ}$ 104, 2002

World Health Organization. Global tuberculosis control: WHO report. Geneva; 2003.

Wolinsky E. Statement of the Tuberculosis Committee of the Infectios Diseases Society of America. CID 1993;16:627-628.

Zhang Y, Heym B, Allen B. The catalase-peroxidase gene and isoniazid resistance in tuberculosis. Nature 1992;358:591. 


\section{ANEXO 1}

Unidade:

\section{PESQUISA DE PRONTUÁRIO}

Data da pesquisa de prontuário

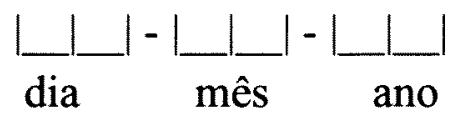

1- Nome

2- Número de registro na unidade.

3- Data de nascimento.

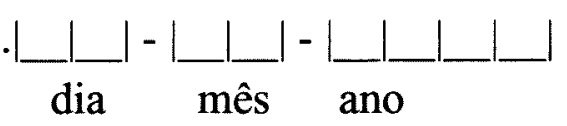

4- Idade (no momento do diagnóstico de TB).

5- Sexo (1-masc e 2-fem.).

6- Nome da mãe

7- Com domicílio (1-sim e 2-não)

8-Data do primeiro HIV positivo

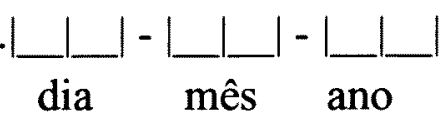

9- Presidiário (1-sim 2-não e 9-ign.).

Data ingresso

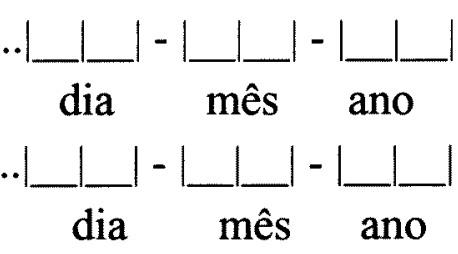

Data saída.

10- Consumo de bebidas alcoólicas (1-sim, 2-não e 9-ign.).

11-Usuário de droga injetável( 1-sim, 2-não e 9-ign.). 


\section{Tratamentos realizados}

12- Uso de AVR (1 -sim, 2-não, 9- ign)

13- Uso de HAART ( 1 - sim, 2 -não, 9 ign).

Resultado de principais exames

14- CD4/CD8 anterior ao diagn. de TB data.

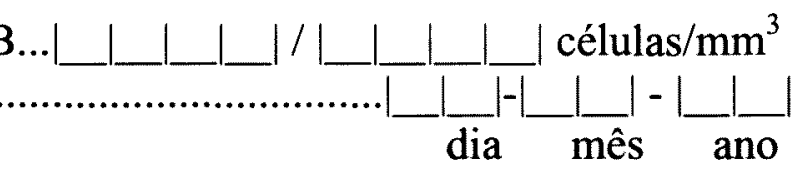

\section{Carga Viral}

15- Carga viral anterior ao diagn. de TB data

Internações anteriores a tuberculose(relacionadas à infecção pelo HIV ou posteriores à descoberta da infecção)

Códigos de hospital 1= Santa Casa; 2 = Hospital Guilherme Álvaro; $3=$ Hospital dos Estivadores; $4=$ Hospital São José; 5= Hospital Santo Amaro; 6= outro hospital de Santos; $7=$ outro hospital regional; 8= outro hospital fora da região.

16- $\left.1^{\text {a }}\right)$ Hospital

Motivo

data.

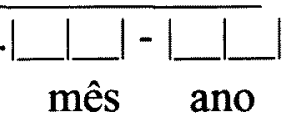

17- $\left.2^{\mathbf{a}}\right)$ Hospital Motivo

data 
18- $3^{\mathrm{a}}$ ) Hospital.

Motivo

data.

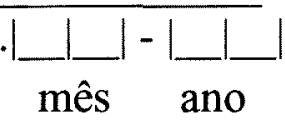

19- $4^{a}$ ) Hospital.

Motivo

data.

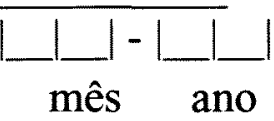

20-Tratamentos de tuberculose

$H$-Isoniazida

R-Rifampicina

$P$-Pirazinamida

$S$ - Estreptomicina

E-Etambutol

T- Etionamida

U-Outras drogas

Início

Data

Drogas

Tipo de alta

1- cura

2- abandono

3 - transferência

4-óbito

5 -em trat.

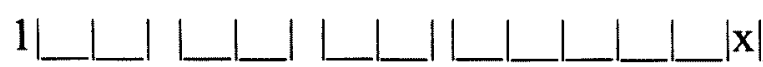

$2 \mid$

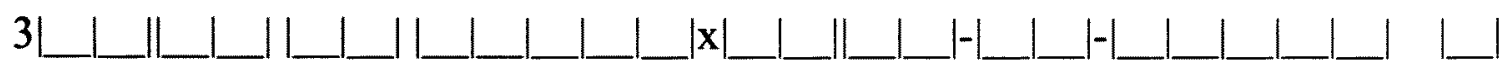

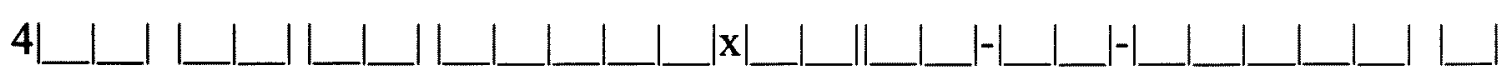
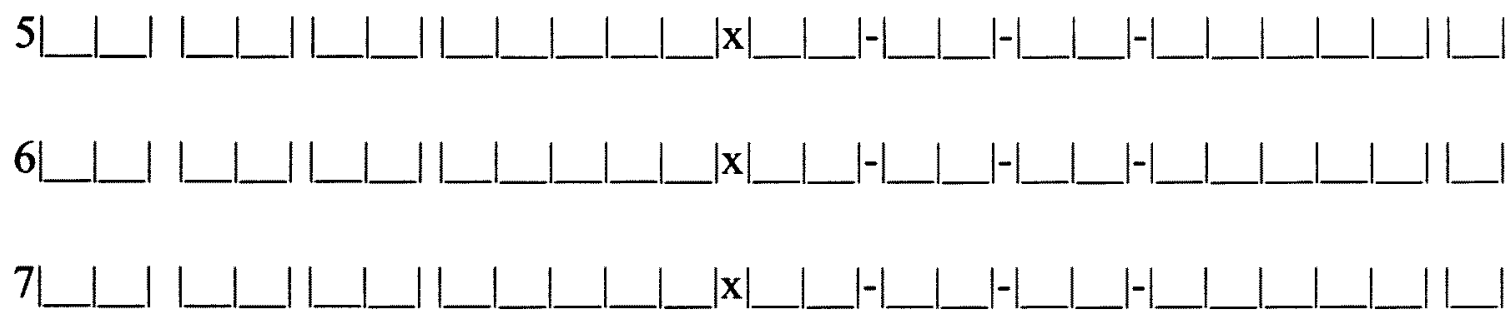

$8 \mid$ 
$9 \mid$

9

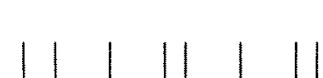

\section{(1)}

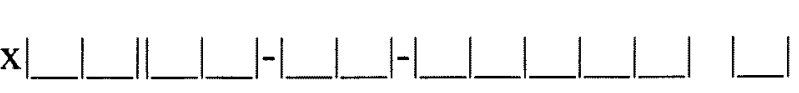

21-BK

(resultado $1=$ positivo; $2=$ negativo)

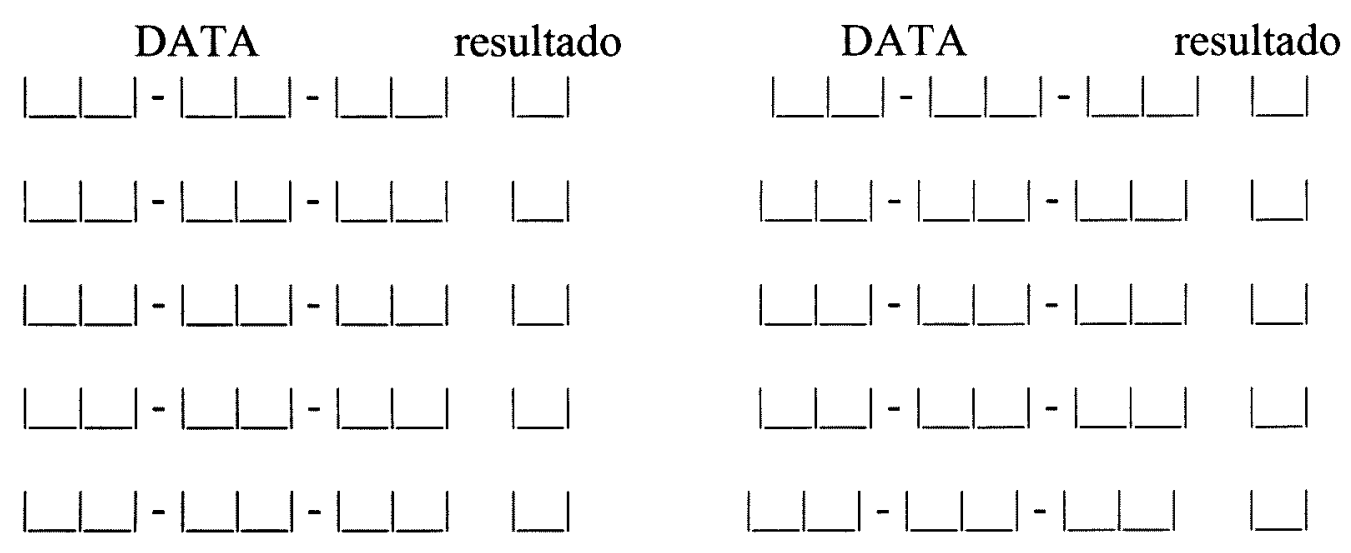

Se resultado da cultura for positivo, anotar data do exame e resultado do antibiograma segundo códigos: $1=$ não resistente a nenhuma droga; $2=$ resistente a pelo menos uma droga, $3=n \tilde{a} o$ realizado;

Antibiograma em $\left.\left.\right|_{\text {dia }}|/|\right|_{\text {mês }}|/|_{\text {ano }}^{\mid} \mid+\ldots$. resultado

se resposta $=2$, descrever a quais antibióticos a bactéria é resistente.

22-Data último comparecimento a unidade

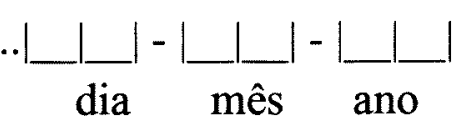

23- Data do óbito

$$
\frac{|+|}{\text { dia }}||_{\text {mês }}\left|\frac{\mid}{\text { ano }}\right|
$$

24- Causa óbito ( 1- TB, 2-não TB e 9-ign.). 